Article

\title{
Variabilities in PM2.5 and Black Carbon Surface Concentrations Reproduced by Aerosol Optical Properties Estimated by In-Situ Data, Ground Based Remote Sensing and Modeling
}

\author{
Alessandro Damiani ${ }^{1, *}$, Hitoshi Irie ${ }^{1}$, Kodai Yamaguchi ${ }^{1}$, Hossain Mohammed Syedul Hoque ${ }^{1,2}$, \\ Tomoki Nakayama $^{3}$ (D), Yutaka Matsumi ${ }^{2}$ (D), Yutaka Kondo ${ }^{4}$ and Arlindo Da Silva ${ }^{5}$ \\ 1 Center for Environmental Remote Sensing, Chiba University, Chiba 263-8522, Japan; \\ hitoshi.irie@chiba-u.jp (H.I.); k.yamaguchi@chiba-u.jp (K.Y.); \\ hoque.hossain.mohammed.syedul@a.mbox.nagoya-u.ac.jp (H.M.S.H.) \\ 2 Solar-Terrestrial Environment Laboratory, Nagoya University, Nagoya 456-0000, Japan; matsumi@nagoya-u.jp \\ 3 Faculty of Environmental Science, Graduate School of Fisheries and Environmental Sciences, \\ Nagasaki University, Nagasaki 853-0000, Japan; t-nakayama@nagasaki-u.ac.jp \\ 4 National Institute of Polar Research, Tokyo 120-0000, Japan; kondo.yutaka@nipr.ac.jp \\ 5 NASA Goddard Space Flight Center, Global Modeling and Assimilation Office, Washington, DC 20771, USA; \\ arlindo.m.dasilva@nasa.gov \\ * Correspondence: alecarlo.damiani@gmail.com; Tel.: +81-43-290-3869
}

\section{check for}

updates

Citation: Damiani, A.; Irie, H.; Yamaguchi, K.; Hoque, H.M.S.; Nakayama, T.; Matsumi, Y.; Kondo, Y.; Da Silva, A. Variabilities in PM2.5 and Black Carbon Surface Concentrations Reproduced by Aerosol Optical Properties Estimated by In-Situ Data, Ground Based Remote Sensing and Modeling. Remote Sens. 2021, 13, 3163. https://doi.org/10.3390/rs13163163

Academic Editor: Dimitrios Balis

Received: 14 June 2021

Accepted: 2 August 2021

Published: 10 August 2021

Publisher's Note: MDPI stays neutral with regard to jurisdictional claims in published maps and institutional affiliations.

Copyright: (C) 2021 by the authors Licensee MDPI, Basel, Switzerland. This article is an open access article distributed under the terms and conditions of the Creative Commons Attribution (CC BY) license (https:/ / creativecommons.org/licenses/by/ $4.0 /)$.
Abstract: Because of the increased temporal and spatial resolutions of the sensors onboard recently launched satellites, satellite-based surface aerosol concentration, which is usually estimated from the aerosol optical depth (AOD), is expected to become a strategic tool for air quality studies in the future. By further exploring the relationships of aerosol concentrations and their optical properties using ground observations, the accuracies of these products can be improved. Here, we analyzed collocated observations of surface mass concentrations of fine particulate matter (PM2.5) and black carbon (BC), as well as columnar aerosol optical properties from a sky radiometer and aerosol extinction profiles obtained by multi-axis differential optical absorption spectroscopy (MAX-DOAS), during the 2019-2020 period. We focused the analyses on a daily scale, emphasizing the role of the ultraviolet (UV) spectral region. Generally, the correlation between the AOD of the fine fraction (i.e., fAOD) and the PM2.5 surface concentration was moderately strong, regardless of considerations of boundary layer humidity and altitude. In contrast, the fAOD of the partial column below $1 \mathrm{~km}$, which was obtained by combining sky radiometer and MAX-DOAS retrievals, better reproduced the variability of the PM2.5 and resulted in a linear relationship. In the same manner, we demonstrated that the absorption AOD of the fine fraction (fAAOD) of the partial column was related to the variability of the BC concentration. Analogous analyses based on aerosol products from the Modern-Era Retrospective analysis for Research and Applications, Version 2 (MERRA-2) confirmed these findings and highlighted the importance of the shape of the aerosol profile. Overall, our results indicated a remarkable consistency among the retrieved datasets, and between the datasets and MERRA-2 products. These results confirmed the well-known sensitivity to aerosol absorption in the UV spectral region; they also highlighted the efficacy of combined MAX-DOAS and sky radiometer observations.

Keywords: remote sensing; aerosol; PM2.5; sky radiometer; DOAS

\section{Introduction}

Aerosol particles influence the climate by the direct reflection of solar radiation, as well as indirect enhancement of cloud reflectivity through their role as cloud condensation nuclei. Nevertheless, substantial uncertainty remains regarding their radiative effects on the Earth's climate [1]. While radiation scattering by particles causes an overall atmospheric cooling and negative radiative forcing, light-absorbing particles will warm the atmosphere and potentially cause a positive radiative forcing. In particular, when deposited on snow, 
light-absorbing particles lower the albedo, increase the absorption of solar radiation, and trigger various feedback mechanisms [2].

Exposure to fine particulate matter (i.e., atmospheric particulate with an aerodynamic diameter of $<2.5 \mu \mathrm{m}$ (PM2.5)) can cause respiratory and cardiovascular diseases, e.g., [3]. In most urbanized regions, PM2.5 concentrations are usually measured by ground-based instruments belonging to national/municipal surface monitoring networks. There are far fewer instruments located outside of urban areas, which makes it challenging to extrapolate monitoring network observations over large regions.

Since the launch of the Moderate Resolution Imaging Spectroradiometer (MODIS) sensor in 2003, which enabled the monitoring of atmospheric aerosols with unprecedented resolution $(10 \times 10 \mathrm{~km})$, it has become clear that surface PM2.5 estimations from satellite remote sensing can complement surface observations e.g., [4]. Because of the increased temporal and spatial resolution of the sensors onboard recently launched satellites e.g., [5,6], satellite-based estimates of the surface aerosol concentration are expected to become a strategic tool for air quality studies in the near future [7]. The algorithms that have been developed to estimate PM2.5 surface concentrations rely largely on satellite-based aerosol optical depth (AOD) and ancillary information concerning meteorological parameters (e.g., boundary layer altitude and humidity) and/or aerosol types. Various methods are currently available to reproduce surface PM2.5 [8].

The satellite-based estimation of black carbon (BC) concentrations has attracted the attention of the scientific community [9]. Among the various types of aerosols, $\mathrm{BC}$ is considered the most important radiation absorber [10]. It is the second-most important climate forcer after carbon dioxide and absorbs light over the entire solar spectrum. Black carbon aerosols are emitted by the incomplete combustion of carbonaceous matter, such as fossil fuels and biomass. Generally, the aging process after the initial emission causes BC aerosols to become internally mixed with non-BC inorganic and/or organic compounds. Unlike other aerosol particles, $\mathrm{BC}$ is usually not water active; the hygroscopic growth of $\mathrm{BC}$-containing particles depends on the amount and composition of the materials mixed with it, e.g., [11,12]. Currently, only the Ozone Monitoring Instrument (OMI) onboard the Aura satellite routinely provides information concerning the optical properties of absorbing aerosols by exploiting the well-known sensitivity of aerosol absorption in the ultraviolet (UV) spectral range [13]. However, these datasets are characterized by a limited accuracy that is largely caused by the low spatial resolution of the instrument. Moreover, for quantitative estimates on UV absorption, accurate estimates of aerosol altitude are also required but the UV-index sensitivity to near surface absorption is limited.

Overall, near-surface pollution estimates by passive remote sensing are difficult, as cases of elevated aerosol have to be excluded and absorption (spectral) information is needed.

Further explorations of the relationship between aerosol concentrations and their optical properties using ground observations could improve the accuracies of the satellitebased algorithms used to estimate surface aerosol concentrations. Within this framework, we used recent ground-based observations to reproduce the variability of the aerosol surface concentration by joining columnar optical properties from a sky radiometer and aerosol extinction profiles from multi-axis differential optical absorption spectroscopy (MAX-DOAS) instruments. In addition to PM2.5, by exploiting the sensitivity of the UV spectral region to the aerosol absorption, we proved that $\mathrm{BC}$ mass concentrations can be reproduced with sufficient accuracy, including in regions characterized by low aerosol loadings. We further evaluated our findings by using the corresponding aerosol products of the Modern-Era Retrospective analysis for Research and Applications, Version 2 (MERRA-2) and demonstrated consistency among the datasets and MERRA-2 products. 


\section{Datasets and Methods}

Measurements of surface aerosol mass concentrations, aerosol optical properties, aerosol extinction profiles, and tropospheric gases were conducted from 12 November 2019, to 31 December 2020, at Chiba University, Japan (Figure 1).

(a)

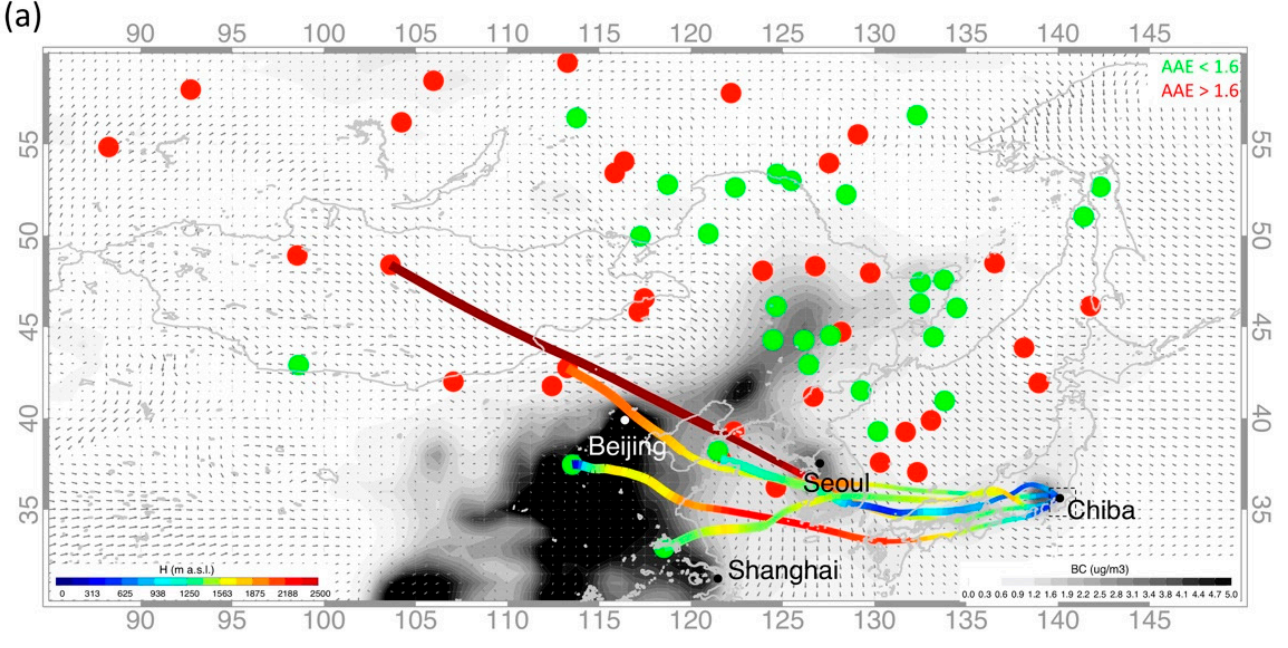

(b)

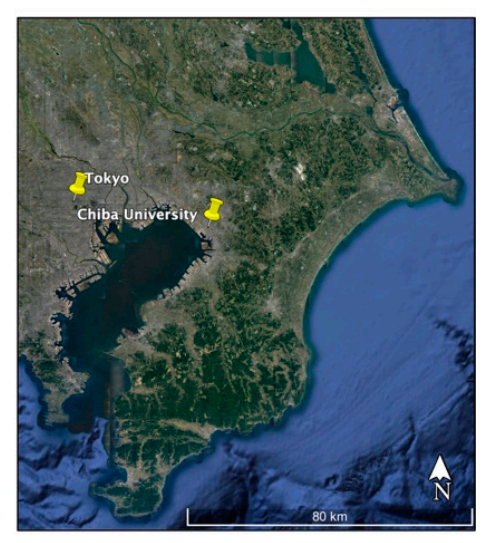

Figure 1. (a) The 72-h backward trajectories for days with large surface BC concentrations at Chiba overlain on a map of the distribution of the mean surface BC (gray scale) concentration and wind speed/direction at $10 \mathrm{~m}$ a.s.l., as estimated by MERRA-2 for November 2019 to December 2020. The arrival height and arrival time at Chiba University station (b) were set at $500 \mathrm{~m}$ a.s.l. and at 0300 UTC (1200 JST), respectively. Colors show the boundary layer height. The increasing thick line of the trajectories highlights the $0-24 \mathrm{~h}, 25-48 \mathrm{~h}$, and $49-72 \mathrm{~h}$ periods. The green and red circles show the geographic origin of the 72-h backward trajectories for days characterized by AAEs of $<1.6$ and $>1.6$, respectively, as estimated by sky radiometer observations. Only days with an AE $>1$ and low RH are shown.

Chiba University is located in an urban/industrial area in the southeastern part of Tokyo (Figure 1b). It is a core station of SKYNET (http:/ / atmos3.cr.chiba-u.jp/skynet/, accessed on 13 January 2021), which is an international observation network based on sky radiometer observations. The network is used in aerosol-cloud-radiation interaction research [14] and for the validation of satellite observations, e.g., $[6,15,16]$. The MAX-DOAS facilities at the same site [17] provide continuous information concerning tropospheric gases and aerosol extinction profiles.

The main features of the instruments used in this study are summarized in Table 1.

It should be noted that most of the observations were recorded during the period of the spreading of the COVID-19 pandemic. In particular, a state of emergency (similar to the European lockdown, but without strict legal restrictions) in Japan was declared for April and May 2020, and traffic was substantially reduced. Although we expect some limited influence of the pandemic on the anthropogenic absorbing aerosols, we cannot quantify it since BC data were not available for most of 2019 (i.e., pre-COVID). No evident changes for PM2.5 were identified.

\subsection{Datasets}

\subsubsection{Profiles of the Aerosol Extinction Coefficient from MAX-DOAS}

The MAX-DOAS instrument utilized the differential absorption structures of the oxygen collision complex $\left(\mathrm{O}_{4}\right)$ in the UV and visible (VIS) wavelengths to derive aerosol and trace gases information [18]. It was equipped with a UV-VIS spectrometer, which was located indoors, while a telescope unit located outdoors collected reference and off-axis observations. Scattered sunlight was measured at 15-min intervals, at various elevation angles of $2^{\circ}, 3^{\circ}, 4^{\circ}, 6^{\circ}, 8^{\circ}$, and $70^{\circ}$. This approach (i.e., limiting elevation angles to $<10^{\circ}$ ) was adopted to minimize the systematic error in the oxygen collision complex fittings and achieve a high sensitivity in the lowest layers [18]. The reference spectra were recorded at 
an elevation angle of $70^{\circ}$ instead of $90^{\circ}$ to minimize the variations in the signals measured at each elevation angle. High-resolution spectra were recorded from 310 to $515 \mathrm{~nm}$, with a full width at half maximum of $0.4 \mathrm{~nm}$ at 357 and $476 \mathrm{~nm}$. The wavelength calibration was based on the solar spectrum of [19] and was performed daily to account for the possible long-term degradation of the spectrometer. The retrieval was based on DOAS and optimal estimation methods; it was carried out using the Japanese vertical profile retrieval algorithm version 2 [20].

The main steps of the algorithm are the DOAS fittings, followed by the retrieval of the aerosol profile and, finally, of the trace gases. The differential slant column density of trace gases was retrieved using the DOAS technique. Second and third order polynomials were fitted to account for the wavelength-dependent offset and the slowly varying effect over wavelengths mainly due to molecular and particle scattering, respectively. The differential slant column density of trace gases was retrieved based on fitting windows and absorption cross-section data [20]. Then, the AOD and the vertical profiles of the aerosol extinction coefficient (AEC) were retrieved using the optimal estimation method and a lookup table of the box air mass factor vertical profile based on the Monte Carlo Atmospheric Radiative Transfer Simulator (MCARaTS). For cloud screening, measurements with the retrieved AOD higher than 3 and relative humidity over water for the $0-1 \mathrm{~km}$ layer higher than $90 \%$ were excluded [17].

In various studies, aerosol optical properties from our MAX-DOAS sensors were compared with co-located lidar observations, and results were satisfactory [20,21]. The uncertainty in the retrieved AOD and AEC profiles was further reduced by averaging the data from four collocated MAX-DOAS instruments [17]. Details of the procedures used and error estimates were reported by Irie et al. [20,21].

\subsubsection{Aerosol Optical Properties from the Sky Radiometer}

Within the SKYNET network, the sky radiometer at Chiba University conducts observations of direct and angular sky radiances with a temporal resolution of $10 \mathrm{~min}$. Here, we used estimates of AOD, single scattering albedo (SSA), and absorbing AOD (AAOD) at 340, 380, 400, 500, 675, and $870 \mathrm{~nm}$ retrieved through the Sky Radiometer analysis package from the Center for Environmental Remote Sensing (SR-CEReS) version 1 [22]. The SKYRAD pack version 5 [23] was implemented within the SR-CEReS for near-real-time data purposes. The sky radiometer used an on-site calibration method to determine the calibration constant [24] and the solar disk scan method to calculate the solid viewing angle [25]. Observations recorded under cloudy conditions were screened out using the procedure described in [26]. The uncertainties in the retrieved AOD and SSA were approximately \pm 0.02 and \pm 0.05 , respectively $[22,27]$.

Differently from AERONET, the azimuthal scan of SKYNET only explores one side for each inversion analysis. Nevertheless, we recorded observations at both sides in this study, achieving two AOD and inversion values every $10 \mathrm{~min}$.

The accuracy of SKYNET retrieved parameters has been recently reviewed by Nakajima et al. [14]. Under low aerosol conditions, a small relative bias in the determination of AOD could cause significant deviations in the computed AE [14]. On the other hand, sometimes SSA values were overestimated when compared with other networks [14] with differences at NIR wavelengths larger than those at UV. Therefore, the error tends to increase with decreasing AOD. The SKYNET SSA data were recently evaluated over the UV-NIR spectral range regarding SSA values retrieved from AERONET, MFRSR, and Pandora observations at Yonsei University, Seoul, South Korea, during the Korea-United States Air Quality Study (KORUS-AQ) international field campaign [22]. This study provided the first comparisons of the SKYNET and MFRSR SSA retrievals at UV wavelengths and found SSA differences of around 0.02 for $\lambda \leq 500 \mathrm{~nm}$ and a larger value of 0.05 at $870 \mathrm{~nm}$ (note that the aerosol load in Seoul is usually larger than that of our location).

Despite the application of its cloud screening procedure [26], cloud contamination can still be a potential error source [14]. Nevertheless, in this study, we limited the issue by 
using daily values. Moreover, we further screened daily records by retaining only those estimated with many observations recorded during the day (see Section 2.2). As a reference, the average number of SKYNET observations per day of the employed dataset was \#42. In this way, the possible impact of cloudiness is expected to be strongly attenuated. Then, coupling SKYNET data with MAX-DOAS observations, which adopted an independent cloud screening method, further ensures that cloudiness would not affect our results.

Within this context, we highlight that AERONET Level 2.0 products with a final calibration, i.e., the product recommended for publication, are computed for all-optical depths. Still, SSA and a complex index of refraction are limited to AOD greater than 0.4 at $440 \mathrm{~nm}$. Such conditions are rarely fulfilled, even in countries more polluted than Japan. Within this context, our attempt fosters the use of daily observations (to reduce the uncertainty), particularly at UV wavelengths where the AOD is usually higher and the SSA is more reliable.

\subsubsection{Mass Concentrations of BC}

Ambient mass concentrations of $\mathrm{BC}$ were estimated by the continuous soot-monitoring system (COSMOS) [28,29], which is a filter-based optical instrument. A photometer measured the transmittance of light at $565 \mathrm{~nm}$, while particles were deposited on it. COSMOS was equipped with an electric jacket heater to remove volatile organic aerosol before collecting BC particles with a filter. This was achieved by heating a section of the inlet to $300^{\circ} \mathrm{C}$. The accuracy of $\mathrm{BC}$ measurements by COSMOS [30] was estimated to be approximately $10 \%$, based on comparisons with measurements recorded by a single particle soot photometer $[29,31]$. The detection limit of COSMOS is $0.047 \mu \mathrm{g} / \mathrm{m}^{3}$ [32].

\subsubsection{Mass Concentrations of PM2.5}

The PM2.5 observations were conducted by means of a compact PM2.5 instrument [33]. The calculation of the PM2.5 mass concentration was based on the distribution of light scattering intensity by considering the relationship between scattering intensity and particle size. Tests performed in the laboratory suggested that the sensor could detect particles with diameters of $\geq 0.3 \mu \mathrm{m}$ and estimate PM2.5 mass concentrations of $\leq 600 \mathrm{mg} / \mathrm{m}^{3}$. Therefore, potentially, the instrument could miss part of the smaller fine-mode particles. However, data from this sensor have demonstrated good agreement with data from standard instruments during short campaigns performed at Chiba University in 2019 and 2018 [15]; the sensitivity variation is $<10 \%$ [33]. Unlike standard monitors, the compact instrument can provide a PM2.5 mass concentration under ambient conditions. Based on a further characterization of the instrument carried out during the investigation period, its PM2.5 estimates exhibited accuracy similar to equivalent measurements from collocated standard instruments at a relative humidity (RH) of $<60 \%$, although an increasing discrepancy usually developed at higher RH values. Because a clear sky was a necessary condition for collecting aerosol optical properties, days characterized by elevated $\mathrm{RH}$ were rare in our datasets. They were screened out in most of the analyses (see Section 2.2).

\subsubsection{MERRA-2 Reanalysis}

MERRA-2 is NASA's latest reanalysis and includes online aerosol fields that interact with model radiation fields [34,35]. It is based on a coupling of the Goddard Earth Observing System, Version 5 Earth system model with the Goddard Chemistry Aerosol Radiation and Transport aerosol model. The resolution is $0.5^{\circ} \times 0.625^{\circ}$ with 72 vertical layers from the surface to about $80 \mathrm{~km}$. Below $1 \mathrm{~km}$, the thickness of the layers is about $125 \mathrm{~m}$. The model treats the sources, sinks, and chemistry of dust, sea salt (SS), sulphate $\left(\mathrm{SO}_{4}\right)$, and hydrophobic and hydrophilic black and organic carbon (OC). The AOD is calculated offline by a Mie code using the simulated mass concentration of each tracer and the corresponding optical properties. In MERRA-2, aerosol (i.e., AOD) and meteorological observations are jointly assimilated. Therefore, MERRA-2 provides useful information to investigate the 
connection between aerosols and optical properties. In accordance with previous works e.g., [34], MERRA-2 PM2.5 values were estimated as follows:

$$
\mathrm{PM} 2.5=\left[\text { dust2.5] }+[\mathrm{SS} 2.5]+\mathrm{BC}+1.4 \times[\mathrm{OC}]+1.375 \times\left[\mathrm{SO}_{4}\right]\right.
$$

The current version of MERRA-2 does not include nitrates. Nitrogen oxide (NOx) emissions in East Asia have been rapidly increasing over the past decade, and therefore this limitation could affect the accuracy of the MERRA-2 PM2.5 estimates.

Table 1. List of instruments used at Chiba University from 12 November 2019, to 31 December 2020, and the associated retrieved datasets used in this study. Acronyms: black carbon (BC), aerosol optical depth (AOD), absorption aerosol optical depth (AAOD), single scattering albedo (SSA), fine-mode fraction (FMF), aerosol extinction coeffiocient (AEC), planetary boundary layer height (PBLH).

\begin{tabular}{|c|c|c|c|c|c|}
\hline Instrument & Measurements & Wavelength (nm) & Retrieved Parameter & $\begin{array}{c}\text { Time Resolution } \\
\text { (min) }\end{array}$ & References \\
\hline COSMOS & Transmittance of light & 565 & Ambient BC mass conc. & $10 *$ & Kondo et al. [29] \\
\hline POM-02 (skyradiometer) & Direct and angular sky radiance & $\begin{array}{c}340,380,400,500,675 \\
870,1020\end{array}$ & AOD, AAOD, SSA, FMF & $10^{* *}$ & $\begin{array}{c}\text { Mok et al. [22]; } \\
\text { Hashimoto et al. [23] }\end{array}$ \\
\hline Compact PM2.5 & Light scattering intensity & 625 & PM2.5 & 1 & Nakayama et al. [33] \\
\hline MAX-DOAS & Scattered sunlight & $310-515$ & $\mathrm{AOD}, \mathrm{AEC}[0-1 \mathrm{~km}]$ & 15 & Irie et al. $[20,21]$ \\
\hline
\end{tabular}

* Original time resolution: $1 \mathrm{~min}$; ${ }^{*}$ See Section 2.1.2 for further details.

MERRA-2 data were used to compare with and put our results into a broader context (except for the bottom panels of Figure 6, when we exploited MERRA to extrapolate the partial column concentrations from our measurements of PM2.5 and BC surface concentration).

\subsection{Methods}

In the following procedure, to reduce uncertainty, we used daily median values of data recorded at different time resolutions (Table 1) within 9:00 a.m. to 3:00 p.m. LT [27]. In this way, by focusing on the median instead of the average, we reduced the influence of potential cloud-contaminated outliers. Because observations of surface aerosol concentration were usually recorded consistently, while the availability of optical property data was dependent on the weather conditions (i.e., a clear sky), we limited the comparisons to days with at least $2 \mathrm{~h}$ of observations of optical properties. This ensured that the atmospheric conditions on most investigated days were fairly homogeneous, with a frequent occurrence of clear sky, low humidity, an elevated height of the planetary boundary layer, and high pressure.

Dust aerosol episodes are usually rare on the east coast of Japan. Nevertheless, to exclude any significant dust influence, when comparing surface concentrations with optical properties, we removed data with a small Ångström exponent (AE; i.e., values < 1.0) [36].

The AAOD for various wavelengths $(\lambda)$ (i.e., $340,380,400,500,670,870 \mathrm{~nm}$ ) was computed as follows:

$$
\operatorname{AAOD}(\lambda)=\operatorname{AOD}(\lambda) \times[1-\operatorname{SSA}(\lambda)]
$$

The fine-mode fraction (FMF) of aerosol particles with a diameter of $<2.5 \mu \mathrm{m}$ is the ratio of the fine-mode aerosol optical depth (i.e., fAOD) to the total AOD (i.e., F2.5 = fAOD/AOD). Its computation relied on the particle size distribution (radii from 0.012 to $16.540 \mu \mathrm{m}$ ) retrieved from the sky radiometer (based on the number concentrations and the mean size-bin radius, an AOD is calculated for each size-bin. The fAOD is the AOD from all sizes smaller than the threshold, i.e., 1.25 um radius). The fine-mode AAOD (i.e., fAAOD) was defined as fAAOD $=$ AAOD $\times$ F2.5.

The absorption Ångström exponent (AAE) values were calculated following the procedure reported by [27] over the range $340-870 \mathrm{~nm}$, as follows:

$$
\ln [\mathrm{AAOD}(\lambda)]=\mathrm{a}-\mathrm{AAE} \times \ln (\lambda)
$$

with a being the intercept. 
Most of the following analyses were based on data recorded in the UV spectral range. Then, in some cases, we also reported the results in the VIS (i.e., $550 \mathrm{~nm}$ ) by using AE and AAE indexes. Since the composition of the particles is not well known, potentially, the transition could introduce additional uncertainty.

In some of the analyses in this study, we combined the aerosol profile information from MAX-DOAS and columnar aerosol optical properties from the sky radiometer as follows:

$$
\mathrm{fAOD} \lambda[0-1 \mathrm{~km}]=\operatorname{AOD} \lambda[0-1 \mathrm{~km}] \times[\mathrm{F} 2.5]
$$

In our approach, the fine AOD of the partial column below $1 \mathrm{~km}$ (i.e., fAOD[0-1 km]) corresponded to the mean AEC of the partial column at $357 \mathrm{~nm}$ retrieved from the MAXDOAS instrument multiplyed by the F2.5 parameter. The AEC profile used in this study was estimated by combining the AEC profiles from four collocated MAX-DOAS instruments (for further details, see [17]). Then, column-based F2.5 values were retrieved from the sky radiometer.

Following the above approach, we also defined the fine AAOD of the partial column (i.e., fAAOD $[0-1 \mathrm{~km}]$ ) as follows:

$$
\mathrm{fAAOD} \lambda[0-1 \mathrm{~km}]=\mathrm{fAOD} \lambda[0-1 \mathrm{~km}] \times[1-\mathrm{SSA} \lambda]
$$

This was based on the column-based SSA values retrieved from the sky radiometer. In Equation (5), we used the SSA at $340 \mathrm{~nm}$ without any interpolation. This assumption was justified by the short spectral distance between the MAX-DOAS AEC at $357 \mathrm{~nm}$ and the $340 \mathrm{~nm}$ band of the sky radiometer.

Previous studies have shown that an elevated RH (e.g., >70\%) tends to increase the AEC of urban aerosols far above its dry-condition level, e.g., [37]. However, when conditions are very dry, the relationship between AEC and PM2.5 is linear. Therefore, most of the following analysis is based on observations recorded under low humidity conditions. We retained only days with an average $\mathrm{RH}$ of $<70 \%$ for the partial column below $1 \mathrm{~km}$ (based on the retrieved $\mathrm{H}_{2} \mathrm{O}$ concentration from the NCEP pressure and temperature reanalysis data); this resulted in a surface $\mathrm{RH}$ that was always $<50 \%$, as recorded from the weather station. Our approach allowed an improved comparison between BC mass concentrations, recorded at standard temperature and pressure after removing, by heating, volatile organic aerosol, and PM2.5 concentrations estimated under ambient conditions.

Using the model vertical velocity, 72-h backward trajectories based on the HybridSingle Particle Lagrangian Integrated Trajectory (HYSPLIT) model 4 [38] were also calculated. The arrival height and time were set at $500 \mathrm{~m}$ a.s.l. (i.e., the middle height of the lowest 1-km layer retrieved from MAX-DOAS) and at 0300 UTC (1200 JST), respectively.

\section{Results}

Although we conducted our observations in an urban environment within the most populous metropolitan area worldwide (i.e., the Greater Tokyo Area) and local emissions drive the variability in surface aerosol mass concentrations, Figure 1 suggests a meteorological modulation of the aerosol concentrations measured at Chiba University station. Figure 1a shows that most air masses arriving at Chiba originated in the northeast regions of China, Korea, and Siberia. However, when the highest BC concentrations were recorded (see box in Figure 5e,f), the associated air masses previously traveled over the region of very high BC emissions in northeastern China (involving the cities of Beijing, Shanghai, and Seoul).

The time series of the daily BC (black) and PM2.5 (red) observations recorded at Chiba University during the investigation period is presented in Figure 2a. As expected, there was a positive correlation between the two datasets with the Pearson correlation coefficient (r) equal to 0.85 . Both PM2.5 and BC mass concentrations were higher in winter than in the rest of the year. No BC observations were available for August and September 2020, due to the failure of heater system of COSMOS. 


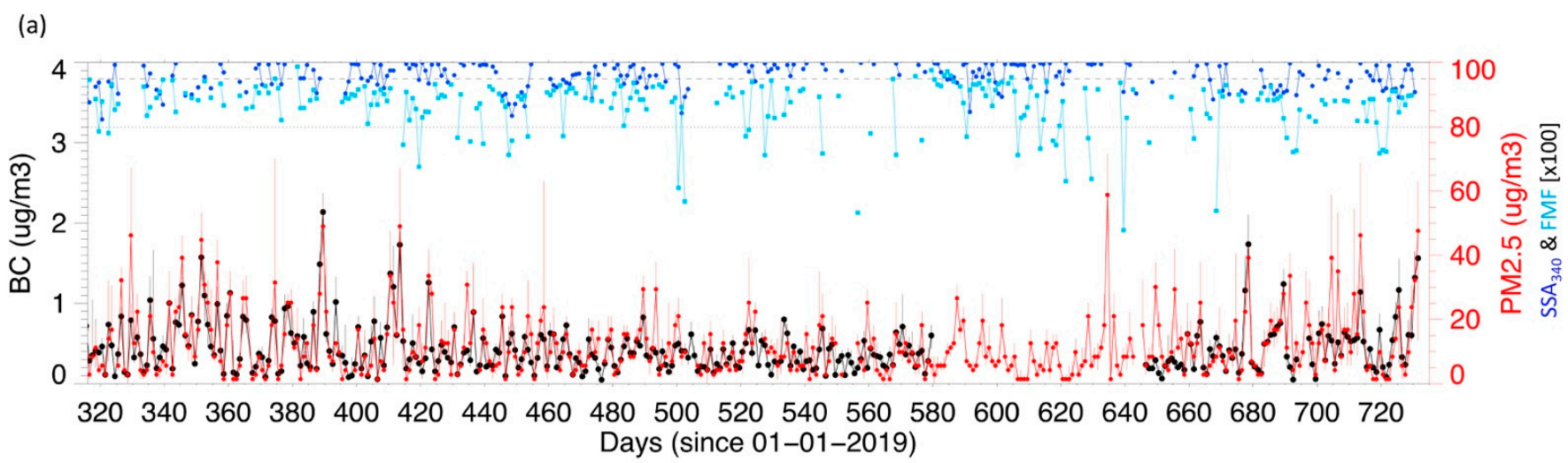

(b)

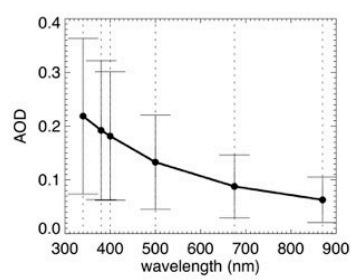

(c)

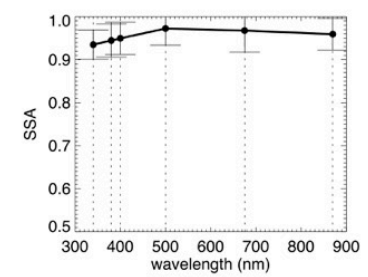

(d)

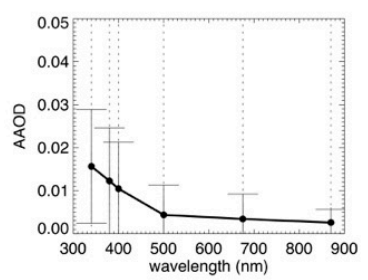

Figure 2. Main panel (a): time series of the daily surface BC (black line) and PM2.5 (red line in the opposite axis) mass concentrations recorded at Chiba University, from 12 November 2019 to 31 December 2020. Error bars show the 67\% ranges of BC and PM2.5, respectively. The SSA at $340 \mathrm{~nm}$ (violet points) and fine-mode fraction (FMF) of aerosol particles with a diameter of $<2.5 \mu \mathrm{m}$ (i.e., F2.5; cyan squares) estimates are shown on the opposite axis (expressed as values $\times 100$ ). Bottom panels: mean AOD (b), SSA (c), and AAOD (d) over the investigation period retrieved by sky radiometer observations at $340,380,400,500,675$, and $870 \mathrm{~nm}$. Error bars show the standard deviation.

The SSA at $340 \mathrm{~nm}$, estimated by the sky radiometer (violet points), was frequently $<0.95$. Moreover, the F2.5 values (cyan squares) were usually around $90 \%$ (with an AE often $>1$; not shown). Sometimes, high peaks in particle mass concentrations corresponded to a lack of information regarding aerosol optical properties. Such peaks frequently developed under conditions of low planetary boundary layer height (PBLH) and substantial cloudiness, which prevented observations of optical properties.

The main aerosol optical parameters averaged over the investigation period are shown in the top panels. The AOD usually displayed a clear wavelength dependence with values in the UV spectral range higher than values in the VIS and near infrared (NIR) (Figure 2b). The low SSA at UV wavelengths suggested that, in addition to BC, organic aerosols (i.e., brown carbon, $\mathrm{BrC}$ ) played a large role (Figure 2c). The resulting AAOD values, calculated using Equation (2), are shown in Figure 2d. Overall, the features highlighted here match the peculiar characteristics of the East Asian aerosols and contrast with other aerosol types such as biomass burning, dust, and urban/industrial recorded in other locations [39].

To exploit the well-known sensitivity to the aerosol absorption in the UV spectral region, we based the results of this study largely on observations recorded within this spectral region (i.e., at $340 \mathrm{~nm}$ for the sky radiometer and at $357 \mathrm{~nm}$ for MAX-DOAS). Most of the results were then reported at $550 \mathrm{~nm}$ using AE or AAE values. Because the aerosol loading is usually quite low at our location (the average AOD was approximately 0.15 at $500 \mathrm{~nm}$ and the days with AOD at $340 \mathrm{~nm}$ larger than 0.25 were $27 \%$ of the total during the investigation period; Figure $2 b$ ) and due to the wavelength dependence of the AOD (Figure 2b), the quality of the SSA was likely to be higher at UV wavelengths [40]. Therefore, we expect that this approach also increased the accuracy of the AAOD estimates.

Figure 3a,c shows the correlations of BC and PM2.5 mass concentrations with wind speed. In general, concentrations decreased with increasing wind speed; this negative correlation was more apparent for BC and less apparent for PM2.5 (probably due to more sea salt particles at stronger winds). Although the contribution from remote sources cannot 
be neglected (Figure 1), the findings indicate a central role for local emissions with respect to particle concentrations. Winds were mainly from the south during the investigation period (Figure $3 b, d$ ) and there was no clear impact of wind direction on particle concentration. It should be noted that only part of the dataset here shown (i.e., data recorded under clear sky conditions, $\mathrm{RH}>50 \%$ and $\mathrm{AE}>1$ ) were used in the following comparison with the aerosol optical properties.

(a)

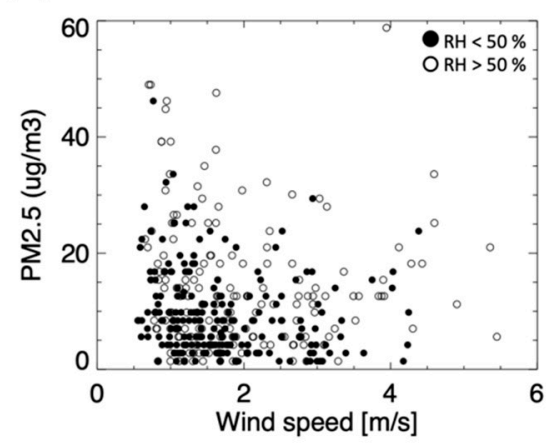

(c)

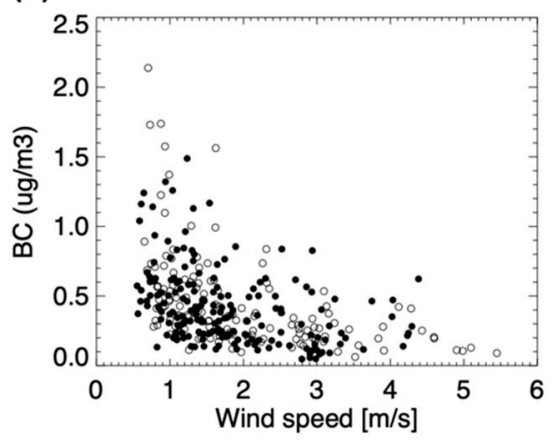

(b)

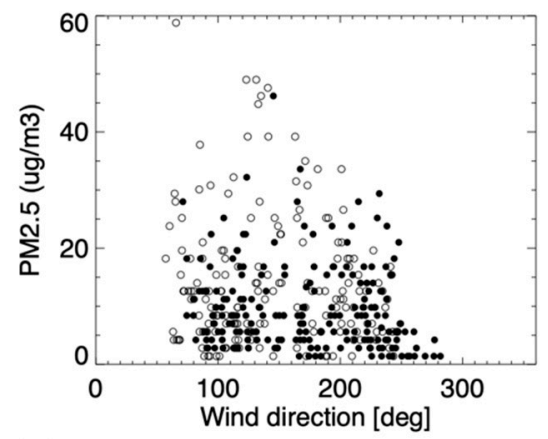

(d)

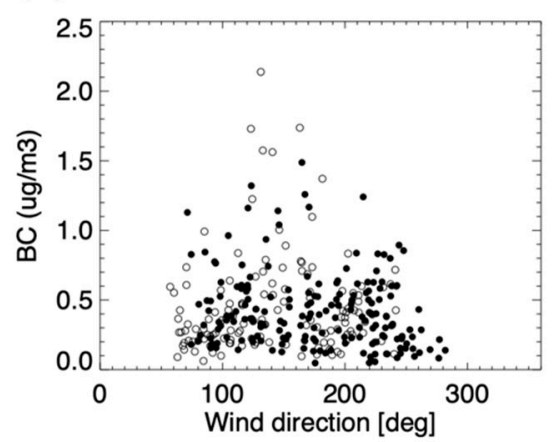

Figure 3. Scatter plots of daily surface PM2.5 mass concentrations relative to wind speed (a) and wind direction (b); scatter plots of BC relative to wind speed (c) and wind direction (d). Filled black circles highlight days with $\mathrm{RH}<50 \%$.

We complemented our observations with the MERRA-2 reanalysis. Because both aerosol and meteorological observations were assimilated in MERRA-2, we used MERRA-2 as a further reference to connect the aerosol concentrations and optical properties and to generalize our findings. Monthly PM2.5 and BC observations for 2019 and 2020 are presented in Figure 4, together with the corresponding estimates from MERRA-2. While both PM2.5 (Figure 4a) and BC (Figure 4c) particles usually had high concentrations from November to February and lower values during the rest of the year, only BC was characterized by a well-defined seasonality in both observation data and reanalysis data.

Although MERRA-2 did not reproduce the changes in PM2.5 particles, it captured the variability of the BC $(r=0.95)$ but overestimated its concentration. During the investigation period, the mean BC/PM2.5 ratio was $0.05 \pm 0.03$ for the observations, while it was slightly higher $(0.08 \pm 0.05)$ for MERRA-2 data. During the past few years, Japan has experienced a large improvement in air quality and BC mass concentrations have significantly decreased. For example, BC in Tokyo decreased by a. factor of about 3 between 2003 and 2010, following the introduction of local regulations of transport emissions [41]. Moreover, in recent years, the strict measures adopted in areas upwind (e.g., China) lowered the levels further. Because anthropogenic emissions (except for biomass burning) are not updated in the model [35], MERRA-2 tended to overestimate the current BC concentrations. 
(a)

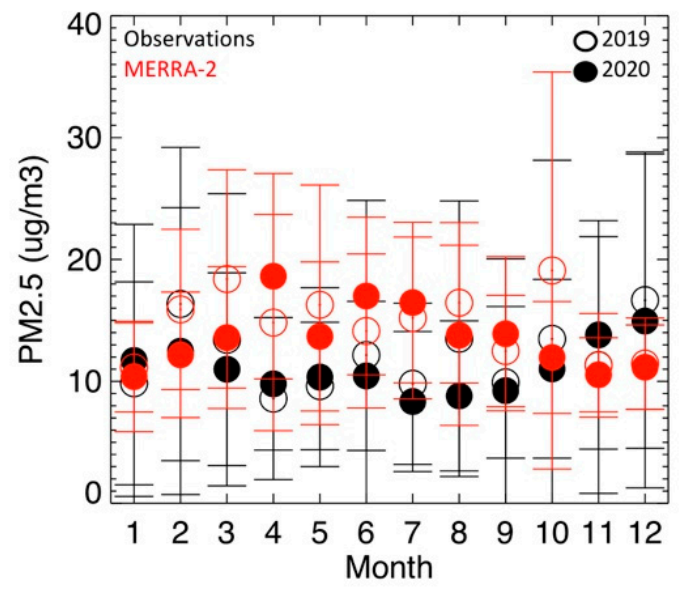

(b)

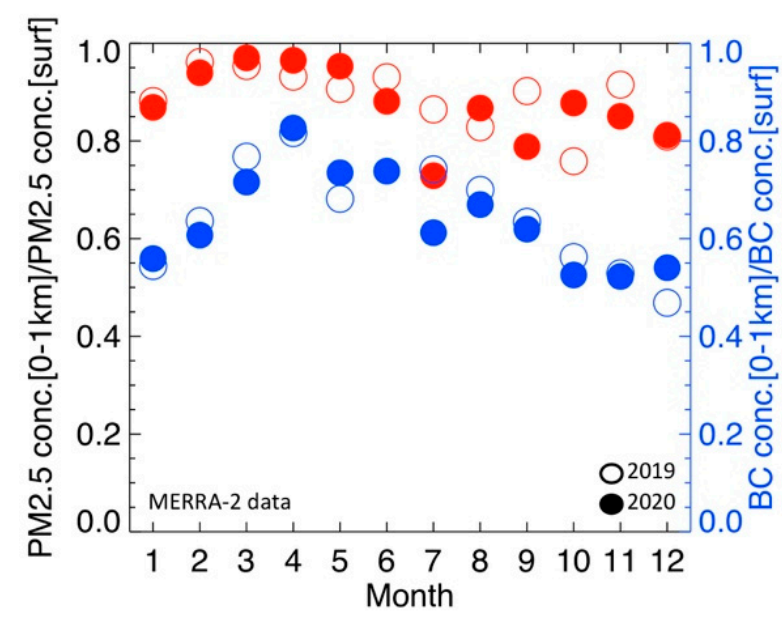

(c)

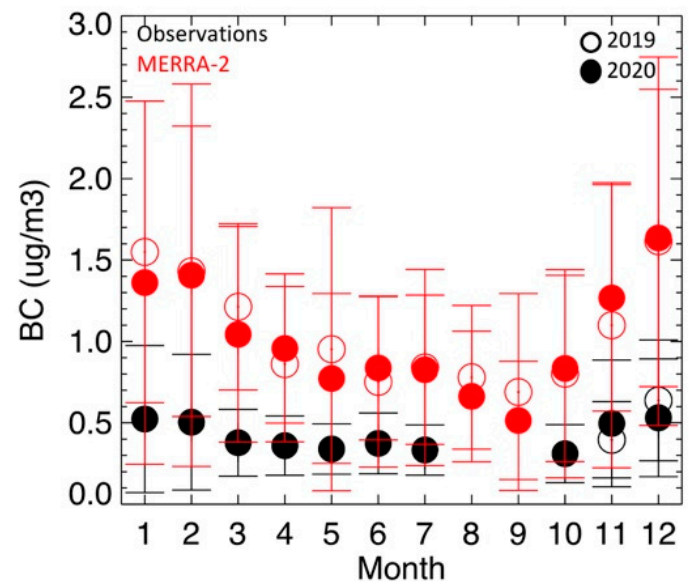

(d)

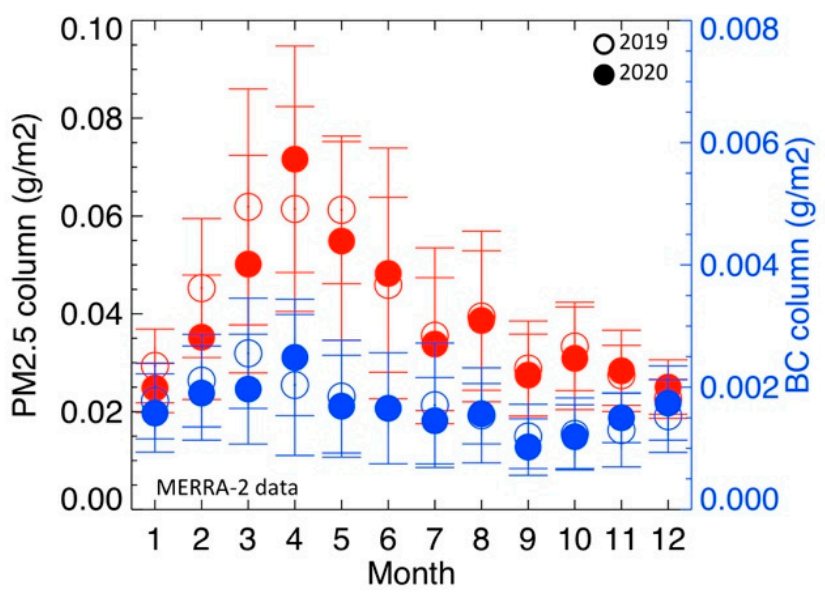

Figure 4. (a) Monthly surface PM2.5 mass concentrations observed at Chiba University (black) and estimated by MERRA-2 (red); (b) MERRA-2 monthly ratios of PM2.5 (red) and BC (blue) mean concentrations of the partial column $(<1 \mathrm{~km})$ to surface concentrations; (c) monthly average surface BC mass concentrations observed by COSMOS (black) and estimated by MERRA-2 (red); (d) monthly PM2.5 and BC total columns estimated by MERRA-2. Filled and empty circles show data for 2020 and 2019, respectively.

Most of the following analyses focused on the variability of the partial column below $1 \mathrm{~km}$. It is critical to examine the ratios of the average concentrations of both PM2.5 and BC within the partial column to the corresponding surface concentrations. Because we only measured the surface concentrations, this information could only be acquired for MERRA-2. In panel (b) of Figure 4, we show that the PM2.5 ratio was usually within the range of 0.8-1, while the $\mathrm{BC}$ ratio was slightly lower (around $0.6-0.8$ ). These estimates confirmed that the PBL at Chiba was characterized by a homogeneous particle distribution. To estimate the PBLH, we exploited data from a lidar collocated with the other instruments. The system was a two-wavelength (1064 and $532 \mathrm{~nm}$ ) polarization sensitive $(532 \mathrm{~nm})$ Mie-scattering LiDAR [42]. Due to the lack of overlap between the laser beam and the field of view of the telescope, the lowest height of the retrieved profile was about $100 \mathrm{~m}$ (e.g., Irie et al., 2015). The LiDAR was part of AD-Net, which is a LiDAR network for the observation of the vertical distribution of aerosols in East Asia. During the investigation period, the average PBLH was $>1 \mathrm{~km}$ (1150 $\mathrm{m}$ a.s.l.). This average was raised by a further $200 \mathrm{~m}$ if only clear sky days (as below) were selected. 
The MERRA-2 columns of PM2.5 and BC (Figure 4d) showed a peak in spring; potentially, higher $\mathrm{BC}$ values were due to springtime agricultural biomass burning in Eastern China, which advected to Japan; they showed lower values in late summer and autumn. This is only partially coherent with the surface concentrations shown in the top panels and highlights the role of the profile shape.

Because aerosol surface mass concentrations were more directly comparable with the fAOD of the partial column (i.e., fAOD[0-1 km]) than with the fAOD of the total column, Figure 5 a shows the scatter plot between the $\mathrm{fAOD}[0-1 \mathrm{~km}]$ and the surface PM2.5 mass concentration for days with an AE $>1$. The moderately low correlation achieved $(\mathrm{r}=0.61)$ was mostly explained by the broad range of RH embraced by the dataset, which was expected to affect both the PM2.5 concentration and the optical properties [37]. When considering only days with low RH conditions (Section 2.2), the correlation ( $\mathrm{r}=0.92$; Figure 5b) was significantly improved and the relationship between the AEC and PM2.5 became linear, as in previous studies $[37,43]$. When the results were reported at $550 \mathrm{~nm}$ using the AE values, a lower slope was observed in the linear regression. The presence of a positive intercept suggested that low aerosol concentrations were likely present in the air below $1 \mathrm{~km}$, regardless of PM2.5 concentrations present at the surface.

(a)

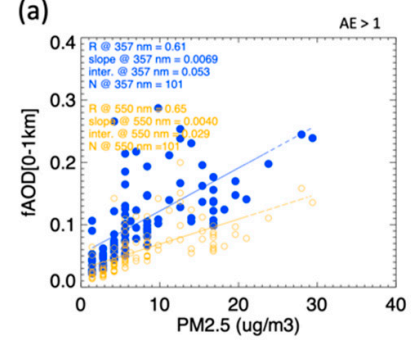

(e)

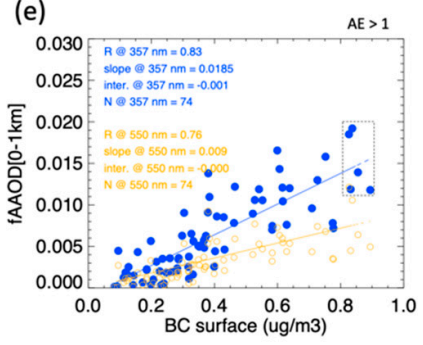

(b)

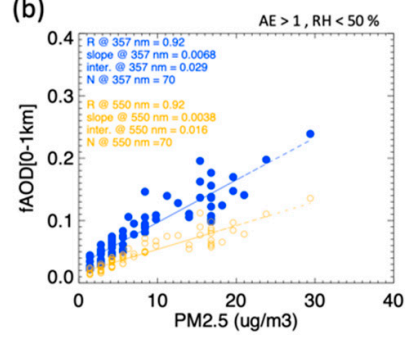

(f)

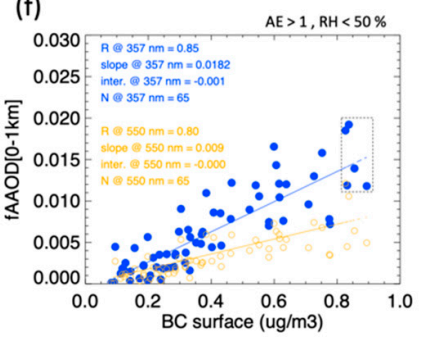

(c)

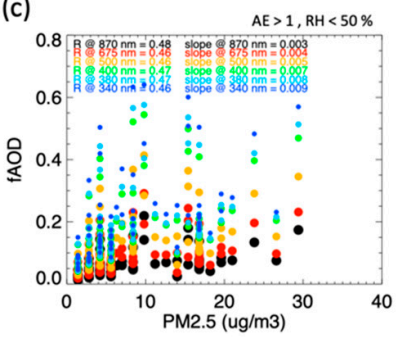

(g)

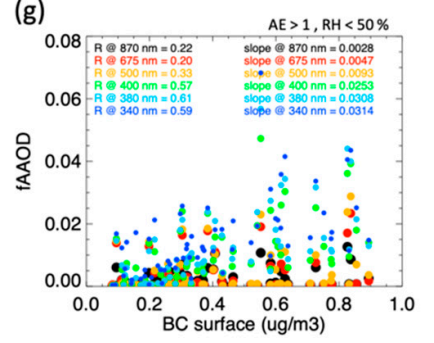

(d)

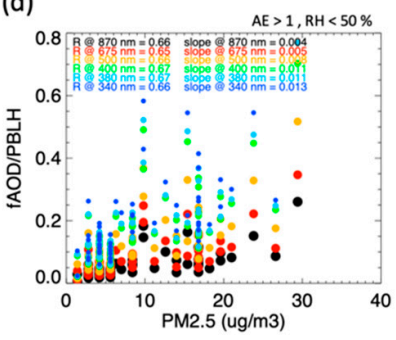

(h)

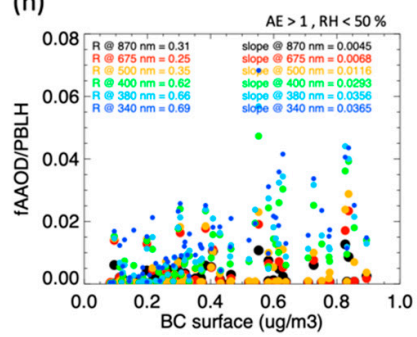

Figure 5. Scatter plots of the observed PM2.5 surface concentrations and fAOD[0-1 km] values of the partial column below $1 \mathrm{~km}(\mathbf{a}, \mathbf{b})$, surface BC concentrations and fAAOD[0-1 km] values of the partial column (e,f), PM2.5 concentrations and fAOD (i.e., total column) (c), and BC concentrations and fAAOD (i.e., total column) (g). Panels (d,h) are identical to (c) and (g), except the fAOD and fAAOD values are divided by the boundary layer altitude. Only days with an AE $>1$ and low $\mathrm{RH}$ were used (as indicated in the top-right corner of each panel). Statistics are included in each panel. The dashed box in $(\mathbf{e}, \mathbf{f})$ highlights the days with the largest BC concentrations; their backward trajectories are shown in Figure 1.

Various previous papers proved the reliability of the aerosol optical properties retrieved from our MAX-DOAS within the PBL compared to co-located LiDAR, sky radiometer, and cavity ring-down spectroscopy observations [20,21]. Figure S1 shows the ability to reproduce the variability of the surface particle concentration from both MAX-DOAS and the co-located LiDAR during the investigated period by applying Equation (4), discussed in Section 2.2. MAX-DOAS better captured the variability of the surface PM2.5 concentration achieving a higher correlation $(R=0.92)$ than Lidar $(R=0.70)$. In addition to the different geometry, this was likely due to the higher accuracy of the observations in the UV spectral range under the low aerosol load, which characterized the period of observations. An additional favorable element could be related to using the average of four MAX-DOAS sensors pointing toward different directions (see Section 2), which probably contributed to capturing the PM2.5 variability. 
Estimates of AAOD recorded by sky radiometers are among the few constraints of the global radiative forcing of BC [44]. However, because of the inclusion of the SSA in their calculation (Equation (2)), AAOD estimates are affected by a larger uncertainty, compared with AOD estimates. Figure 5e shows scatter plots of the relationship between the fAAOD[0-1 km] of the partial column (calculated as described in Section 2.2) and the surface $\mathrm{BC}$ mass concentrations for days with an $\mathrm{AE}>1$. Despite the large uncertainty in $\mathrm{fAAOD}[0-1 \mathrm{~km}]$, there was a robust correlation between the two datasets $(\mathrm{r}=0.83)$. Reporting the results at $550 \mathrm{~nm}$ (by exploiting the AAE values) resulted in a less than halved value of the slope of the regression line and in a slightly lowered correlation coefficient. In contrast to Figure 5a,b, the intercept was negligible in this analysis; the exclusion of the observations recorded under high RH conditions (Figure $5 f$ ) did not change the overall results. Nevertheless, to ensure better comparison (see Section 2.1.2), the following text focuses only on low RH conditions.

Figure $5 c$ is similar to Figure $5 b$, although it shows the fAOD estimated by the sky radiometer at various wavelengths. Generally, the fAOD increased with increasing PM2.5 concentration, but the correlations (range of 0.46-0.48) were much lower in Figure $5 c$ than in Figure 5b. Because we selected only days with low RH conditions, day-to-day differences in the shape of the vertical profiles were likely the cause of this low correlation. Figure $5 \mathrm{~d}$ shows that dividing the fAOD by the LiDAR-based PBLH resulted in an improved correlation (range of 0.65-0.67), although these values remained much smaller than the values shown in Figure $5 b$.

A scatter plot of the skyradiometer-based fAAOD (i.e., the fine AAOD of the total column) at various wavelengths, and the $\mathrm{BC}$ mass concentration under a low humidity and with an $\mathrm{AE}>1$, is shown in Figure 5g. Generally, although fAAOD values roughly increased with the decrease in wavelength, larger values were recorded in correspondence with larger BC concentrations. Nevertheless, the moderate correlations $(0.20<\mathrm{r}<0.61)$ increased in strength from the NIR toward the UV-VIS spectral range. Dividing the fAAOD by the PBLH (Figure 5h) resulted in improved correlations (range of 0.25-0.69), although these values remained lower than the values shown in Figure $5 \mathrm{f}$.

It should be noted that the fine-mode definition of the aerosol size separation at $2.5 \mathrm{um}$ is somewhat larger than the usual threshold at $1 \mathrm{um}$. Since a PM1 instrument was not available at our station, we used this threshold because it allowed a convenient link to PM2.5 in situ data. Although our fine-mode definition could potentially introduce some contribution by sea salt (e.g., under stronger winds) and dust and affecting the linkage with the surface BC mass concentration, differences in using F2.5 instead of F1.0 resulted in being mostly minor (see Figure S1).

The top panels of Figure 6 present the relationship between optical properties and surface aerosol particle concentrations at 550 (or 532) nm, for comparison with the equivalent MERRA-2 parameters. In addition, because MERRA-2 does not provide a vertical profile of the aerosol extinction coefficient of fine aerosols, we performed the following analysis by excluding the F2.5 parameter from Equations (4) and (5).

Figure 6a shows a scatter plot of the AOD[0-1 km] and PM2.5 mass concentration for observations (black) and reanalysis products (red). The AOD datasets were reported at $550 \mathrm{~nm}$ using the respective AE values. Despite the limitations of MERRA-2 PM2.5 (see Section 2.1.5), both the slope and correlation coefficient of the linear regression were very similar to the slope and correlation coefficient of the observations, which indicates a remarkable consistency between the two datasets. However, while the MERRA-2 data had a regression line passing through the origin, the observations exhibited a substantial intercept. 
(a)

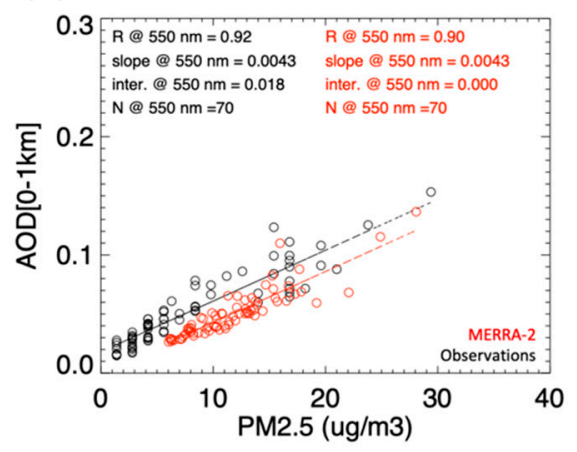

(d)

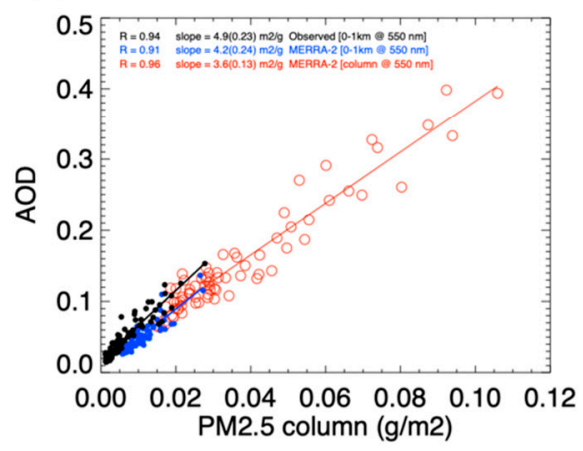

(b)

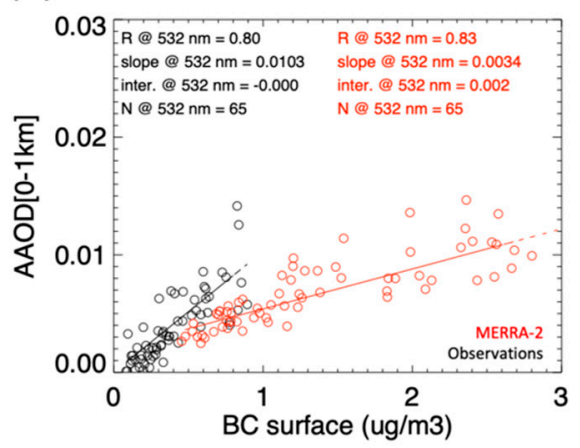

(e)

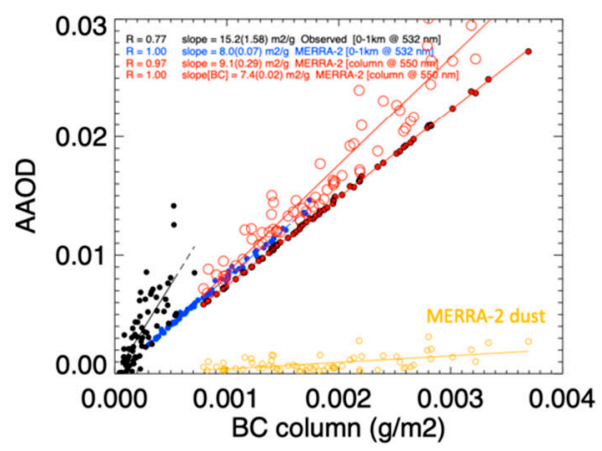

(c)

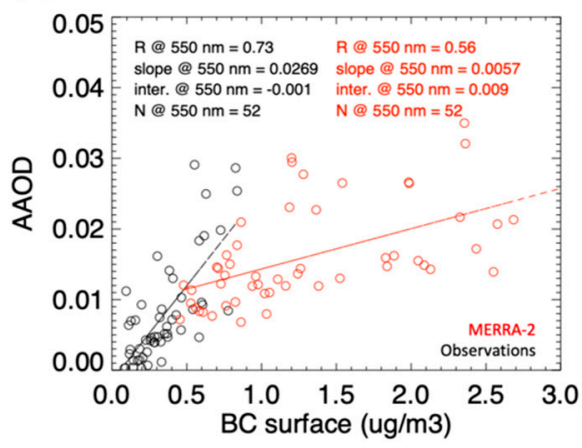

Figure 6. Scatter plots of PM2.5 surface concentrations and AOD[0-1 km] (a), BC surface concentrations and AAOD [0-1 km] (b), BC surface concentrations and the AAOD of the total column (c), PM2.5 total (red) or partial (black and blue) column concentrations and the AOD of the total or partial column (d), and BC total (red) or partial (black and blue) column concentrations and the AAOD of the total or partial column (e). In panel (e), scatter plots of the MERRA-2 AAOD of BC and $\mathrm{BC}$ total column concentration (small filled red points) and the AAOD of fine dust and $\mathrm{BC}$ total column concentration are also shown. Statistics are included in each panel. In panel (d,e) the "observed" PM2.5 and BC partial column was estimated by multiplying the measured surface concentration by the MERRA-based ratio of the mean concentration of the partial column to the surface concentration. Observations: black; MERRA-2 data: red (total column), blue (partial column). Only days with an $\mathrm{AE}>1$ and low $\mathrm{RH}$ are used. Days in panel (c) were further screened based on the AOD [0-1 km]/AOD ratio (see text for details).

Figure $6 \mathrm{~b}$ shows a scatter plot of $\mathrm{AAOD}[0-1 \mathrm{~km}]$ at $532 \mathrm{~nm}$ and surface $\mathrm{BC}$ mass concentration for observations and reanalysis products. Notably, MERRA-2 provides AEC profiles at $532 \mathrm{~nm}$; because AAE values were not available from MERRA-2, we did not report the results at $550 \mathrm{~nm}$. Although MERRA-2 greatly overestimated the observed $\mathrm{BC}$, the correlation coefficients of the two scatter plots were similar. In contrast, the linear regression slope was approximately threefold steeper in the observations than in the MERRA2 data, and a substantial intercept was only present in the MERRA-2 data. For further confirmation of this behavior, we analyzed the columnar AAOD (Figure 6c). Therefore, in addition to focusing on the total column instead of the partial column, the observed aerosol optical properties only relied on the sky radiometer. To reduce the influence of the shape of the vertical profile on this relationship (see Figure $5 \mathrm{~g}$ ), we selected only days with comparable extinction profiles (i.e., we removed outliers based on the AOD[0-1 km]/AOD ratio). Overall, the scatter plot between the AAOD and the $B C$ concentration confirmed the findings shown in Figure $6 \mathrm{~b}$ and indicated a significant difference in the slope of the linear regression between the two datasets. The map in Figure S3a indicates that, during the investigation period, the average $\mathrm{AAOD} / \mathrm{BC}$ values over continents (East Asia and Japan) were always comparable with the slope of the MERRA-2 data shown in panel (c). The average ratios were higher than the observed slope over the open ocean, where the simulated $\mathrm{BC}$ concentrations were very low $\left(\mathrm{BC}<0.3 \mu \mathrm{g} / \mathrm{m}^{3}\right.$; see Figure 1 and Figure S3a). 
After replacing PM2.5 surface concentrations with the PM2.5 total column in MERRA2 data, an improved correlation $(\mathrm{r}=0.96)$ with the total AOD and a slope of $3.6 \mathrm{~m}^{2} / \mathrm{g}$ were obtained (red points in Figure $6 \mathrm{~d}$; cf. Figure $6 \mathrm{a}, \mathrm{d}$ ). Subsequently, we examined the correlation between the MERRA-2 AOD[0-1 km] and the mean PM2.5 concentration within the partial column (blue points). A similar correlation was observed, along with a slope greater than the total column slope.

To compare the MERRA-2 partial column results with the observations for each day, we estimated the "observed" PM2.5 partial column by multiplying the measured surface concentration by the MERRA-based ratio of the mean concentration of the partial column to the surface concentration (see Figure $4 \mathrm{~b}$ ). In this manner, we allowed the meteorology, which was considered in the reanalysis, to modulate the observed estimates of the partial column. The resulting slightly increased correlation coefficient (cf. Figure $6 \mathrm{a}, \mathrm{d}$; observations in black) indicates the effectiveness of this approach. Despite the uncertainties involved in this process, the slope of the linear regression remained close to the corresponding estimate of MERRA-2.

Importantly, retention of the F2.5 parameter in Equation (4) reduced the "observed" slope to $4.4 \pm 0.20 \mathrm{~m}^{2} / \mathrm{g}$ at $550 \mathrm{~nm}$. This value could be interpreted as a rough estimate of the mass extinction coefficient of the PM2.5 particles for our location (Table 2). Kim et al. [45] reported that the mass extinction coefficient for different locations worldwide is in the range of $3.4-8.6 \mathrm{~m}^{2} / \mathrm{g}$. These estimates, obtained by various techniques, depend on the mass extinction efficiencies of the involved aerosol species, as well as the humidity conditions, which affect hygroscopic and non-hygroscopic species to various extents [45-47]. Because we focused on dry conditions, the slope in this study could be more appropriately interpreted in terms of the mass extinction efficiency of PM2.5 particles (Table 2).

Table 2. Estimate of the mass extinction coefficient (MEC) and mass extinction efficiency (MEE) of PM2.5 particles and mass absorption coefficient (MAC) of BC obtained by various techniques, under different conditions, at various locations.

\begin{tabular}{cccc}
\hline Parameter & Estimate & Location & Reference \\
\hline MEC of PM2.5 & $3.4-8.6 \mathrm{~m}^{2} / \mathrm{g}$ & Worldwide locations & Kim et al. [45] \\
MEC of PM2.5 & $4.7 \mathrm{~m}^{2} / \mathrm{g}$ & Seoul (with RH $=60.1 \%$ ) & Kim et al. [46] \\
MEC of PM2.5 & $3.4 \mathrm{~m}^{2} / \mathrm{g}$ & Beijing (with $\mathrm{RH}<40 \%)$ & Jung et al. [47] \\
MEE of PM2.5 & 2.87 to $6.64 \mathrm{~m}^{2} / \mathrm{g}$ & Various cities in China & Cheng et al. [48] \\
MEE of PM2.5 & $4.5 \mathrm{~m}^{2} / \mathrm{g}$ & Developed countries & Hand et al. [49] \\
MEE of PM2.5 & $4.4 \pm 0.20 \mathrm{~m}^{2} / \mathrm{g}$ & Chiba (with $\mathrm{RH}<50 \%)$ & this study \\
MAC of BC & 7.0 to $10.5 \mathrm{~m}^{2} / \mathrm{g}$ & East and South Asia & Matsui [50] \\
MAC of BC & $7.5 \pm 1.2 \mathrm{~m}^{2} / \mathrm{g}$ & Worldwide locations & Bond and Bergstrom [51] \\
MAC of BC & 4.6 to $11.3 \mathrm{~m}^{2} / \mathrm{g}$ & East and South Asia & Cho et al. [52] \\
MAC of BC & 1.6 to $16.6 \mathrm{~m}^{2} / \mathrm{g}$ & Worldwide locations & Cheng et al. [53] \\
MAC of BC & 2.3 to $10.5 \mathrm{~m}^{2} / \mathrm{g}$ & AeroCom model intercomparison project & Koch et al. [54] \\
\hline
\end{tabular}

Similar analyses were performed (Figure 6e), in which we focused on the relationship between the AAOD and BC columns (i.e., both partial and total columns). For reference, the relationship between the total AAOD and the BC column (red empty points) for MERRA-2 was plotted. It was characterized by a high correlation $(r=0.97)$ and a linear regression slope of $9.1 \pm 0.29 \mathrm{~m}^{2} / \mathrm{g}$.

The $\mathrm{BC}$ mass absorption cross-section (MAC[BC]) is a critical parameter linking the $\mathrm{BC}$ atmospheric concentration and climate impact [44]. When multiplied by the mass concentration of a particle, $\mathrm{MAC}[\mathrm{BC}]$ yields the $\mathrm{BC}$ absorption at a specific wavelength According to the findings in previous studies [44,50], the BC mass absorption cross-section can be defined as follows:

$$
\mathrm{MAC}[\mathrm{BC}]=\mathrm{AAOD}[\mathrm{BC}] / \mathrm{BC}[\text { column }]
$$


where $\mathrm{AAOD}[\mathrm{BC}]$ is the aerosol absorption optical depth of $\mathrm{BC}$, and $\mathrm{BC}$ [column] is the column mass concentration of BC.

Previous observation-based studies showed that $\mathrm{MAC}[\mathrm{BC}]$ varies with distance from the source, and therefore with the aging of the aerosols. For example, Bond and Bergstrom [51] reported a value of $7.5 \pm 1.2 \mathrm{~m}^{2} / \mathrm{g}$ for freshly emitted (uncoated) soot particles at $550 \mathrm{~nm}$. However, after emission, condensation processes in the atmosphere cause the $\mathrm{BC}$ particles to become coated, which can enhance their absorption. Overall, the $\mathrm{MAC}[\mathrm{BC}]$ estimated through laboratory or simulations spanned a large range [52-54] (see Table 2).

Following the definition in Equation (6), the slope of the linear regression of the MERRA-2 AAOD $[\mathrm{BC}]$ and $\mathrm{BC}$ columns shown in Figure 6e (small-filled points in red) corresponded to a MAC[BC] of $7.4 \mathrm{~m}^{2} / \mathrm{g}$ (the MERRA-based averages of the MAC[BC] values simulated over the entire east Asian continent and Japan were mostly within the range of 7.5-8; see Figure S3b). Therefore, BC contributed $>80 \%$ of the total absorption (red empty points), which included both fine and coarse aerosols. The contribution of absorbing fine dust aerosols $(<2.5 \mu \mathrm{m}$; orange points) comprised most of the remaining difference in AAOD at our study location (for reference, on average, dust is expected to contribute much more to the total absorption in other Asian locations (e.g., Northern China); see Figure S3c). Despite the small wavelength difference, the linear regression slope of the MERRA-2 partial column (blue points) was very close to the linear regression slope of the MAC[BC]. Because dust aerosol is usually present at high altitudes, the partial column can potentially be more effective, compared with the total column, for estimating the $\mathrm{MAC}[\mathrm{BC}]$, as defined above.

As in the previous panel, the "observed" BC partial column (black points) was estimated by multiplying the measured surface $B C$ concentration by the MERRA-based ratio of the mean $B C$ concentration of the partial column to the surface $B C$ concentration (see Figure $4 b$ ). Although the relative difference between the value of the observed and simulated slope was then reduced (cf. Figure $6 b, e$ ), the slope of the observations remained almost twofold greater than the corresponding value of the MERRA-2 data.

Similar to the discussion above, preserving the F2.5 parameter in Equation (5), we obtained an "observed" slope of $13.0 \pm 1.33 \mathrm{~m}^{2} / \mathrm{g}$ at $550 \mathrm{~nm}$. In contrast to BC, which absorbs radiation over the entire solar spectrum, specific types of $\mathrm{OC}$ (i.e., $\mathrm{BrC}$ ) present a light-absorption coefficient with a strong wavelength dependence. $\mathrm{BrC}$ efficiently absorbs radiation in the near-UV and is characterized by an absorption spectrum that increases from VIS to UV wavelengths [55]. BrC aerosol consists of organic matter with both primary and secondary sources [55]; therefore, it can be emitted together with $B C$ from combustion processes, but can also contain secondary organic aerosol. In addition to burning biomass smoke, which is characterized by a strong spectral dependence caused by $\mathrm{BrC}$, the absorption efficiency of urban aerosol is also often larger in the UV range than in the VIS spectral range $[22,56]$. Considering that the $\mathrm{BrC}$ contribution to the total absorption was expected to be approximately $10 \%$ at $550 \mathrm{~nm}$ for Chiba [57], the value above, despite substantial uncertainty, was within the range of MAC values reported in the literature for aged BC aerosols that are potentially internally mixed with other chemical components [48].

Episodes of dust aerosols are characterized by very high AAE and low AE values [58], but are rare at Chiba University station and were further screened out by selecting only days with an $\mathrm{AE}>1$. The AAE of "pure" BC should be around 1, and the presence of $\mathrm{BrC}$ could potentially increase the AAE because of its enhanced absorption at UV wavelengths [59]. Previous studies have suggested that for internally mixed BC, AAE could vary over a large range because of differences in the size and optical properties of the particles, as well as the wavelengths used for the AAE computation, e.g., [60]. However, the estimated wavelength dependence of AAE can effectively provide an estimate of $\mathrm{BrC}$ and the distinction of sources.

Based on our time series spanning more than a decade, we found that high AAE values in Chiba usually occur in winter. Similarly, other studies have reported a high AAE for the winter months in Japan, e.g., [61], and it has been suggested that the transport of 
biomass burning from east Asia could potentially contribute to this phenomenon. Figure $7 \mathrm{a}$ shows that AAE values had a significant inverse correlation with the wind speed at our location, with a high AAE on days with low wind conditions. Therefore, local sources could be more efficient than remote sources in producing aerosols characterized by significant BrC absorption.
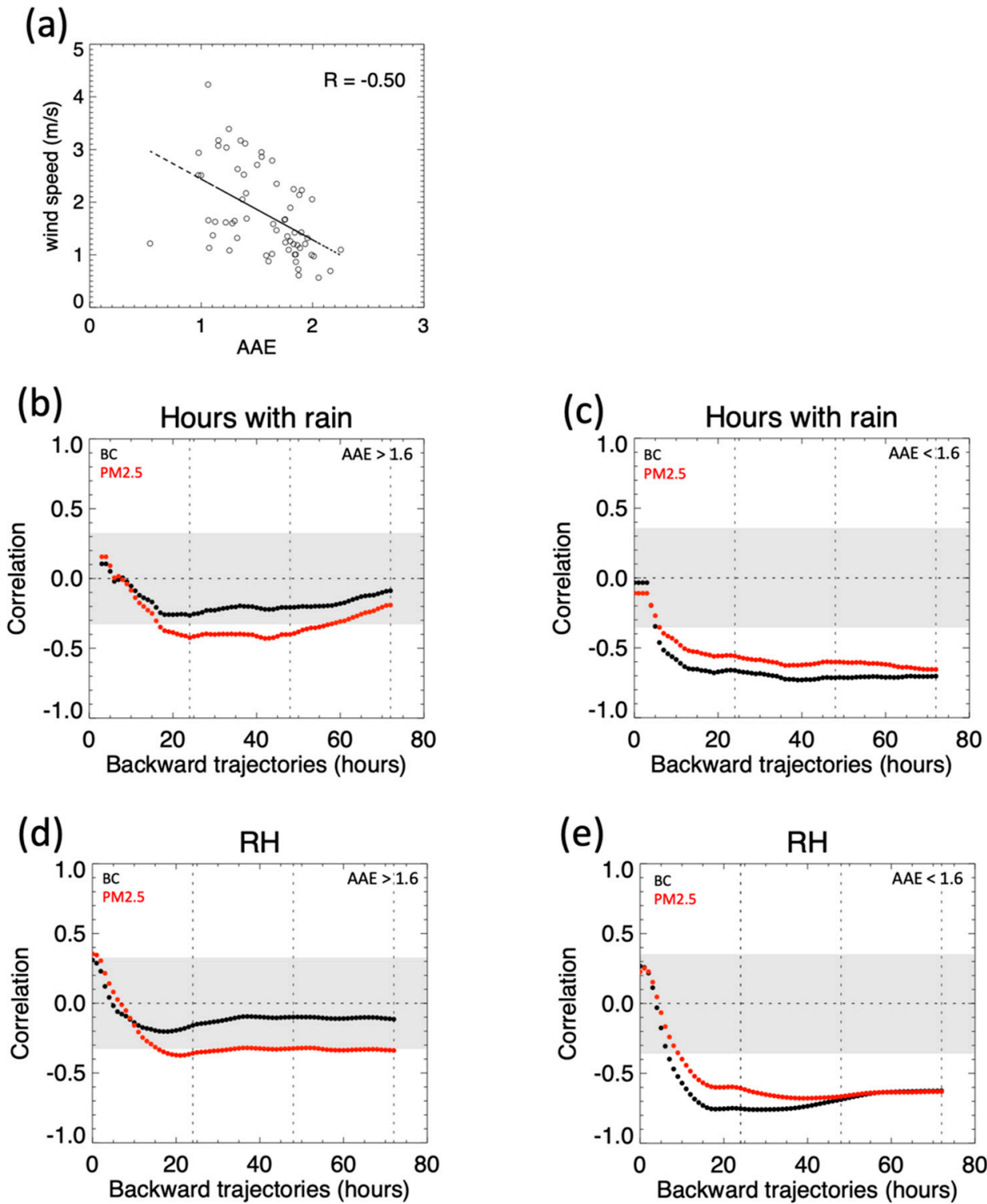

Figure 7. Scatter plot of the wind speed and AAE values for days with an AE $>1$ and low RH (a). Correlations of accumulated hours with rain $(\mathbf{b}, \mathbf{c})$ and average $\mathrm{RH}(\mathbf{d}, \mathbf{e})$ calculated over the increasing time range of the backward trajectories, with respect to BC (black) and PM2.5 (red) values recorded at Chiba University. For each trajectory, averages (or sums) were calculated from Chiba University to the indicated hour in 1-h time intervals. The vertical dashed line highlights the 24, 48, and 72-h time periods. Data outside of the gray box (with $p$-values $<0.05$ ) were statistically significant. Panels $(\mathbf{b}, \mathbf{d})$ : days with an AAE of $>1.6$; panels (c,e): days with an AAE of $<1.6$. Only clear sky days as recorded at Chiba were considered (i.e., very few rainy events occurred within the first hours). In panel (a): $\mathrm{R}=-0.34$ for days with an AAE of $>1.6$ and $\mathrm{R}=0.10$ for days with AAE of $<1.6$.

Because the contribution of $\mathrm{BrC}$ to the total absorption can reach several tens of percent in the UV spectral region [55], the correlation between AAOD and BC (shown in Figures 5 and 6) could be potentially different from the correlation under "pure" BC 
conditions. To further investigate the connection between absorption and the $\mathrm{BC}$ mass concentration, we split the data into two groups, using $\mathrm{AAE}=1.6$ as a threshold. This value roughly corresponded to the median value of the dataset. The geographic origins of the 72-h backward trajectories for days with AAEs of $<1.6$ (green) and $>1.6$ (red) were previously presented in Figure 1a. Although there was no clear distinction between the two groups, most days with an AAE of $<1.6$ were associated with air masses coming from Northeastern China, while days with an AAE of $>1.6$ were associated with air masses coming from regions located further south and west.

Panels (b-e) in Figure 7 show the correlation between the hours with rain accumulated (or the $\mathrm{RH}$ averaged) along the backward trajectories and the BC (or PM2.5) concentrations observed at Chiba for the two datasets. For each trajectory, sums (or averages) were calculated from Chiba to the indicated hour in 1-h time intervals. Overall, the panels show that a significant modulation of the concentrations can be ascribed to rainfall, with larger values of PM2.5 and BC occurring when air parcels did not experience high humidity and/or several hours with rain. Furthermore, this modulation mainly occurred for days with an AAE of $<1.6$ (Figure $7 \mathrm{c}, \mathrm{e})$. In contrast, the correlation was not statistically significant for days with an AAE of $>1.6$ (Figure $7 \mathrm{~b}$,d) when local sources were likely dominant (Figure 7a).

In light of these findings, we further examined the connections between aerosol concentrations and the optical properties of these two groups (Figure S4). For the relationship between fAOD and PM2.5 (first and second columns from the left), the correlations and slopes of the regressions were higher, and the intercepts were lower, with an AAE of $<1.6$; conversely, the correlations and slopes of the regressions were lower, and the intercepts were higher, with an AAE of >1.6. A good agreement between observations and MERRA-2 remained evident in both groups (e.g., Figure S4e,f).

Potentially, the linear regression between AAOD and BC particles could differ slightly, depending on the amount of $\mathrm{BrC}$ associated with BC. However, the third and fourth columns of Figure $\mathrm{S} 4$ show that the correlations and slopes in panels (c) and (d) followed the correlations and slopes in panels (a) and (b). These values were both higher with an AAE of $<1.6$; conversely, they were lower with an AAE of $>1.6$. For both data groups, the slopes in MERRA-2 data were lower: approximately $38 \%$ and $50 \%$ of the observations in Figure S4g,h and Figure S4k,l, respectively.

The mass extinction efficiency is reportedly affected by the relative mass ratio among PM2.5 components (i.e., inorganic, organic, and crustal) [62]. The mass extinction efficiencies of $\mathrm{BC}$, organic matter, and secondary inorganic species are much higher than the mass extinction efficiencies of soil components and sea salt; therefore, larger mass percentages of carbonaceous substances and secondary inorganic species in PM2.5 may lead to greater integrated mass extinction efficiency of PM2.5. Figure S5 in the supplementary material shows the mass percentages of the various PM2.5 components as simulated by MERRA-2 data and observed for the two groups. MERRA-2 roughly reproduced the BC/PM2.5 ratios. However, no evident differences were apparent between the two groups.

As shown in Figure $4 b$, the surface and partial column aerosol concentrations can have a different month-to-month variabilities; this also occurred at the daily scale. MERRA-2 data showed that the average [PM25]0-1 km/[PM25]surf concentration ratios were 0.98 and 0.74 for days with AAEs of $<1.6$ and $>1.6$, respectively. Consistent with these findings, the average $[\mathrm{BC}] 0-1 \mathrm{~km} /[\mathrm{BC}]$ surf ratios were 0.87 and 0.58 for days with AAEs of $<1.6$ and $>1.6$, respectively. Therefore, the different vertical distribution of the particles within the first kilometer partially drove the slope of the regression line in MERRA-2 data and in some observations. When examining the correlations between optical properties and partial column concentrations instead of the surface concentrations (Figure S4i-1), the relative differences in slopes between the two groups (Figure S4e-h) were reduced (for observations) or absent (for MERRA-2). 


\section{Discussion and Conclusions}

This study evaluated the consistencies of observations of surface aerosol concentrations and their associated aerosol optical properties, as estimated by sky radiometer and MAX-DOAS observations recorded at Chiba University (Japan) from November 2019 to December 2020. It showed that partial column (below $1 \mathrm{~km}$ ) optical properties better reproduced the variability of surface aerosol concentrations, compared with the total columnar-based information. In this manner, we demonstrated that the variabilities of the PM2.5 and BC mass concentrations could be simulated with comparable accuracy.

A moderately strong correlation was observed between the columnar AOD of the fine fraction, (i.e., fAOD, obtained from the sky radiometer) and the PM2.5 surface mass concentration and between the AAOD of the fine fraction, (i.e., fAAOD) and BC. Although it has been generally reported that $\mathrm{BC}$ dominates the total absorption in the NIR spectral range, we found higher [fAAOD, $\mathrm{BC}$ ] correlations in the UV range, as well as lower [fAAOD, BC] correlations in the VIS-NIR range; there was no wavelength dependence of the [fAOD, PM2.5] correlation. This suggests that, under the usual low aerosol conditions of Chiba, the wavelength dependence of the AOD resulted in better accuracy of the SSA retrieved at UV wavelengths and worse accuracy of the SSA retrieved at VIS-NIR wavelengths. The stronger correlation between $\mathrm{BC}$ concentrations and fAAOD in the VIS-UV spectral range was likely related to the larger AOD; consequently, the uncertainty in SSA was smaller in the VIS-UV range than in the NIR range [40]. The further benefit of using the UV wavelength is presumably because the surface albedo was likely lower and its day-to-day variability was likely smaller than the corresponding values at larger wavelengths (e.g., [63] and references therein).

By combining sky radiometer and MAX-DOAS retrievals at UV wavelengths, we showed that the $\mathrm{fAOD}$ of the partial column below $1 \mathrm{~km}$ better reproduced the variability of PM2.5 than did the corresponding total column-based estimates. Under low RH conditions, the linear relationship between the two parameters was comparable with the relationship reported in previous studies (e.g., [43]). Similarly, we showed that the fAAOD of the partial column at UV wavelengths was able to satisfactorily reproduce the variability of the surface BC mass concentration. This relationship was also linear, although there was no clear evidence of the influence of humidity. Analyses based on MERRA-2 data confirmed these findings. They suggested that the fAAOD partial column is more effective than the total column for estimating the relationship between $\mathrm{BC}$ absorption and $\mathrm{BC}$ concentration because dust aerosol is usually present at higher altitudes.

When the partial column was used instead of the surface mass concentration, the consistency of the observed aerosol concentrations and their optical properties was further supported by the ability of their corresponding linear relationship to produce rough estimates, under dry conditions, of the mass extinction and mass absorption efficiency of PM2.5 and BC, respectively (Figure 6d,e).

Although we made our observations in an urban environment within the most populous metropolitan area worldwide (i.e., the Greater Tokyo Area) and local emissions have likely driven the variability in surface mass concentrations, we found that the meteorology further modulated this variability. The largest $\mathrm{BC}$ mass concentrations were recorded in the days after the arrival of air masses that had traversed the east Asian region, which is characterized by the highest $\mathrm{BC}$ emissions globally. Moreover, we found that local sources were more efficient, compared with remote sources, for producing aerosols characterized by significant $\mathrm{BrC}$ absorption.

In this study, to reproduce the variability of the $\mathrm{BC}$ mass concentration at ground level, we used aerosol absorption estimates, averaged within the partial column below $1 \mathrm{~km}$, at $\mathrm{UV}$ wavelengths. In addition to $\mathrm{BC}, \mathrm{BrC}$ is expected to play a non-negligible role in this spectral region. Nevertheless, by splitting our observations into two groups using the median of the associated AAE values as the threshold, we revealed only limited differences between the groups when the optical properties were related to concentrations. By relating the AAOD of the partial column to the average particulate matter concentration of the 
same column (instead of the surface concentration), we confirmed that these differences were mainly caused by differences in the profile shape.

The underestimation of light absorption by BC in climate models, compared with observations, has been previously reported. This issue has been frequently addressed by scaling up their parametrized BC mass absorption cross sections (e.g., [64]). On the other hand, previous studies showed a general reasonable agreement between the aerosol optical properties simulated by MERRA and those retrieved from OMI observations, as well as the difficulty simulating absorption optical properties [65]. Here, we found that MERRA-2 did not accurately reproduce the observed relationship between AAOD and BC at Chiba University station; in particular, although the surface $B C$ was largely overestimated, the AAOD remained comparable with the observations (Figure 6e). Profile differences between MERRA and MAX-DOAS and the uncertainty in reporting AAOD from UV to VIS regions (via AAE) likely contributed to this incongruence. Further analysis based on multiple stations will be necessary to clarify this discrepancy.

Exploring the relationships of aerosol concentrations and their optical properties using ground observations could potentially improve the accuracies of satellite-based algorithms used to estimate surface particulate matter. The exploitation of the 3-dimensional information enclosed in the fAOD partial column, which can be more directly linked to the aerosol concentration either at the surface or within an estimated partial column, was an innovative feature of this study. Because of the increasing attention of the scientific community toward developing a satellite-based estimation of the surface $\mathrm{BC}$ concentration (Bao et al., 2019), the approach used in the present study is presumably useful for the validation of future satellite-based algorithms. However, in contrast to standard analyses based on satellite data, here we only focused on clear sky conditions and did not try to improve the relationship by including ancillary information (e.g., [8]). In contrast, we evaluated this relationship under uniform conditions of low humidity, high PBLH, and the absence of coarse particles as determined by accurate in situ observations.

Overall, our results indicate consistency among the observation datasets and MERRA2 data, stressing the well-known sensitivity to aerosol absorption in the UV spectral region and highlighting the efficacy of combining MAX-DOAS and sky radiometer observations.

Supplementary Materials: The following are available online at https: / www.mdpi.com/article/10 $.3390 / \mathrm{rs} 13163163$ / s1, Figure S1: scatter plot between the MAX-DOAS-based fAOD[0-1 km] and the measured PM2.5 concentration compared with the scatter between the lidar-based fAOD[0-1 km] and the PM2.5 concentration, Figure S2: scatter plots between the aerosol optical properties and the surface aerosol mass concentrations as in the original Figure 5 except for adopting the fine-mode definition of the aerosol size separation at $1 \mathrm{um}$ (F1.0) instead of $2.5 \mathrm{um}$ (F2.5), Figure S3: geographic distribution of MERRA-2 data, Figure S4: as in Figures 5 and 6, but for days with an AAE of $>1.6$ and days with an AAE of <1.6, Figure S5: mass ratio of the MERRA-2 PM2.5 components.

Author Contributions: Conceptualization, H.I. and A.D.; methodology, A.D. and H.I.; formal analysis, A.D. and K.Y.; data curation, H.M.S.H., T.N., Y.M., Y.K., A.D.S.; original draft preparation, A.D. All authors have read and agreed to the published version of the manuscript.

Funding: This research was supported by the Environment Research and Technology Development Fund (JPMEERF20192001 and JPMEERF20215005) of the Environmental Restoration and Conservation Agency of Japan, JSPS KAKENHI (grant numbers JP19H04235 and JP20H04320), and the JAXA 2nd research announcement on the Earth Observations (grant number 19RT000351).

Data Availability Statement: Observational data recorded at Chiba University are available on the SKYNET website (http:/ / atmos3.cr.chiba-u.jp/skynet/chiba/chiba.html, accessed on 13 January 2021). MERRA-2 data are available at MDISC, managed by the NASA Goddard Earth Sciences (GES) Data and Information Services Center (DISC).

Acknowledgments: Lidar data were provided by courtesy of AD-Net (https: / www-lidar.nies.go. jp/AD-Net, accessed on 13 January 2021). 
Conflicts of Interest: The authors declare no conflict of interest. The funders had no role in the design of the study; in the collection, analyses, or interpretation of data; in the writing of the manuscript, or in the decision to publish the results.

\section{References}

1. IPPC. Climate Change 2013: The Physical Basis. In Contribution of the Working Group 1 to the Fifth Assessment Report of the Intergovernmental Panel on Climate Change; Cambridge University Press: New York, NY, USA, 2013; p. 1535.

2. Rowe, P.M.; Cordero, R.R.; Warren, S.G.; Stewart, E.; Doherty, S.J.; Pankow, A.; Schrempf, M.; Casassa, G.; Carrasco, J.; Pizarro, J.; et al. Black carbon and other light-absorbing impurities in snow in the Chilean Andes. Sci. Rep. 2019, 9, 4008. [CrossRef] [PubMed]

3. Xing, Y.F.; Xu, Y.H.; Shi, M.H.; Lian, Y.X. The impact of PM2.5 on the human respiratory system. J. Thorac. Dis. 2016, 8, E69-E74. [CrossRef]

4. Wang, J.; Christopher, S.A. Intercomparison between satellite-derived aerosol optical thickness and PM2.5 mass: Implication for air quality studies. Geophys. Res. Lett. 2003, 30, 2095. [CrossRef]

5. Kim, J.; Jeong, U.; Ahn, M.H.; Kim, J.H.; Park, R.J.; Lee, H.; Song, C.H.; Choi, Y.S.; Lee, K.H.; Yoo, J.M.; et al. New era of air quality monitoring from space: Geostationary environment monitoring spectrometer (GEMS). Bull. Am. Meteorol. Soc. 2020, 101, 1-22. [CrossRef]

6. Damiani, A.; Irie, H.; Horio, T.; Takamura, T.; Khatri, P.; Takenaka, H.; Nagao, T.; Nakajima, T.Y.; Cordero, R. Evaluation of Himawari-8 surface downwelling solar radiation by ground-based measurements. Atmos. Meas. Tech. 2018, 11, 2501-2521. [CrossRef]

7. Liu, J.; Weng, F.; Li, Z.; Cribb, M.C. Hourly PM2.5 estimates from a geostationary satellite based on an ensemble learning algorithm and their spatiotemporal patterns over Central East China. Remote Sens. 2019, 11, 2120. [CrossRef]

8. Zhang, G.; Rui, X.; Fan, Y. Critical review of methods to estimate PM2.5 concentrations within specified research region. Int. J. Geo-Inf. 2018, 7, 368. [CrossRef]

9. Bao, F.; Cheng, T.; Li, Y.; Gu, X.; Guo, H.; Wu, Y.; Wang, Y.; Gao, J. Retrieval of black carbon aerosol surface concentration using satellite remote sensing observations. Remote Sens. Environ. 2019, 226, 93-108. [CrossRef]

10. Conrad, B.M.; Johnson, M.R. Mass absorption cross-section of flare-generated black carbon: Variability, predictive model, and implications. Carbon 2019, 149, 760-771. [CrossRef]

11. McMeeking, G.R.; Good, N.; Petters, M.D.; McFiggans, G.; Coe, H. Influences on the fraction of hydrophobic and hydrophilic black carbon in the atmosphere. Atmos. Chem. Phys. 2011, 11, 5099-5112. [CrossRef]

12. Liu, D.; Allan, J.; Whitehead, J.; Young, D.; Flynn, M.; Coe, H.; McFiggans, G.; Fleming, Z.L.; Bandy, B. Ambient black carbon particle hygroscopic properties controlled by mixing state and composition. Atmos. Chem. Phys. 2013, 13, 2015-2029. [CrossRef]

13. Torres, O.; Herman, J.R.; Ahmad, Z.; Gleason, J. Derivation of aerosol properties from satellite measurements of back- scattered ultraviolet radiation: Theoretical basis. J. Geophys. Res. 1998, 103, 17099-17110. [CrossRef]

14. Nakajima, T.; Campanelli, M.; Che, Z.; Estellés, V.; Irie, H.; Kim, S.W.; Kim, J.; Liu, D.; Nishizawa, T.; Pandithurai, G.; et al. An overview of and issues with sky radiometer technology and SKYNET. Atmos. Meas. Tech. 2020, 13, 4195-4218. [CrossRef]

15. Damiani, A.; Irie, H.; Takamura, T.; Kudo, R.; Khatri, P.; Iwabuchi, H.; Masuda, R.; Nagao, T. An intensive campaign-based intercomparison of cloud optical depth from ground and satellite instruments under overcast conditions. SOLA 2019, 15, 198-204. [CrossRef]

16. Hoque, S.; Irie, H.; Damiani, A.; Momoi, M. Evaluation of the GCOM-C aerosol products using ground-based sky radiometer observations. Remote Sens. 2020, 12, 2661. [CrossRef]

17. Irie, H.; Yonekawa, D.; Damiani, A.; Hoque, H.M.S.; Sudo, K.; Itahashi, S. Utilizing continuous multi-component MAX-DOAS observations for the near-surface ozone sensitivity diagnosis at Chiba and Tsukuba, Japan for 2013-2019. Prog. Earth Planet. Sci. 2021, 8, 31. [CrossRef]

18. Hönninger, G.; Von Friedeburg, C.; Platt, U. Multi axis differential optical absorption spectroscopy (MAX-DOAS). Atmos. Chem. Phys. 2004, 4, 231-254. [CrossRef]

19. Kurucz, R.L. Solar Flux Atlas from 296 to 1300 nm. Natl. Sol. Obs. 1984, 1, 240.

20. Irie, H.; Nakayama, T.; Shimizu, A.; Yamazaki, A.; Nagai, T.; Uchiyama, A.; Zaizen, Y.; Kagamitani, S.; Matsumi, Y. Evaluation of MAX-DOAS aerosol retrievals by coincident observations using CRDS, lidar, and sky radiometer in Tsukuba, Japan. Atmos. Meas. Tech. 2015, 8, 2775-2788. [CrossRef]

21. Irie, H.; Kanaya, Y.; Akimoto, H.; Iwabuchi, H.; Shimizu, A.; Aoki, K. First retrieval of tropospheric aerosol profiles using MAX-DOAS and comparison with lidar and sky radiometer measurements. Atmos. Chem. Phys. 2008, 8, 341-350. [CrossRef]

22. Mok, J.; Krotkov, N.A.; Torres, O.; Jethva, H.; Li, Z.; Kim, J.; Koo, J.; Go, S.; Irie, H.; Labow, G. Comparisons of spectral aerosol single scattering albedo in Seoul, South Korea. Atmos. Meas. Tech. 2018, 11, 2295-2311. [CrossRef]

23. Hashimoto, M.; Nakajima, T.; Dubovik, O.; Campanelli, M.; Che, H.; Khatri, P.; Takamura, T.; Pandithurai, G. Development of a new data-processing method for SKYNET sky radiometer observations. Atmos. Meas. Tech. 2012, 5, 2723-2737. [CrossRef]

24. Campanelli, M.; Estellés, V.; Tomasi, C.; Nakajima, T.; Malvestuto, V.; Martínez-Lozano, J. Application of the SKYRAD Improved Langley plot method for the in situ calibration of CIMEL Sun-sky photometers. Appl. Opt. 2007, 46, 2688-2702. [CrossRef] 
25. Uchiyama, A.; Matsunaga, T.; Yamazaki, A. The instrument constant of sky radiometers (POM-02), Part II: Solid view angle 2. Atmos. Meas. Tech. 2018, 11, 5389-5402. [CrossRef]

26. Khatri, P.; Takamura, T. An algorithm to screen cloud-affected data for sky radiometer data analysis. J. Meteorol. Soc. Jpn. 2009, 87, 189-204. [CrossRef]

27. Irie, H.; Hoque, H.M.S.; Damiani, A.; Okamoto, H.; Fatmi, A.M.; Khatri, P.; Takamura, T.; Jarupongsakul, T. Simultaneous observations by sky radiometer and MAX-DOAS for characterization of biomass burning plumes in central Thailand in JanuaryApril 2016. Atmos. Meas. Tech. 2019, 12, 599-606. [CrossRef]

28. Miyazaki, Y.; Kondo, Y.; Sahu, L.K.; Imaru, J.; Fukushima, N.; Kano, M. Performance of a newly designed continuous soot monitoring system (COSMOS). J. Environ. Monit. 2008, 10, 1109-1240. [CrossRef]

29. Kondo, Y.; Sahu, L.; Kuwata, M.; Miyazaki, Y.; Takegawa, N.; Moteki, N.; Imaru, J.; Han, S.; Nakayama, T.; Kim, O.N.T.; et al. Stabilization of the mass absorption cross section of black carbon for filter-based absorption photometry by the use of a heated inlet. Aerosol Sci. Technol. 2009, 43, 741-756. [CrossRef]

30. Ohata, S.; Kondo, Y.; Moteki, N.; Mori, T.; Yoshida, A.; Sinha, P.R.; Koike, M. Accuracy of black carbon measurements by a filter-based absorption photometer with a heated inlet. Aerosol Sci. Technol. 2019, 53, 1079-1091. [CrossRef]

31. Kondo, Y.; Sahu, L.; Moteki, N.; Khan, F.; Takegawa, N.; Liu, X.; Koike, M.; Miyakawa, T. Consistency and traceability of black carbon measurements made by laser-induced incandescence, thermal- optical transmittance, and filter-based photo-absorption techniques. Aerosol Sci. Technol. 2011, 45, 295-312. [CrossRef]

32. Kanaya, Y.; Pan, X.; Miyakawa, T.; Komazaki, Y.; Taketani, F.; Uno, I.; Kondo, Y. Long-term observations of black carbon mass concentrations at Fukue Island, western Japan, during 2009-2015: Constraining wet removal rates and emission strengths from East Asia. Atmos. Chem. Phys. 2016, 16, 10689-10705. [CrossRef]

33. Nakayama, T.; Matsumi, Y.; Kawahito, K.; Watabe, Y. Development and evaluation of a palm-sized optical PM2.5 sensor. Aerosol Sci. Technol. 2018, 52, 2-12. [CrossRef]

34. Buchard, V.; Randles, C.A.; Da Silva, A.M.; Colarco, P.R.; Darmenov, A.; Govindaraju, R.; Smirnov, A.; Hoblen, B.; Ferrare, R.; Hair, J.; et al. The MERRA-2 Aerosol Reanalysis, 1980 Onward. Part II: Evaluation and Case Studies. J. Clim. 2017, 30, 6851-6872. [CrossRef]

35. Randles, C.A.; da Silva, A.M.; Buchard, V.; Colarco, P.R.; Darmenov, A.; Govindaraju, R.; Smirnov, A.; Holben, B.; Ferrare, R.; Hair, J.; et al. The MERRA-2 Aerosol Reanalysis, 1980 Onward. Part I: System Description and Data Assimilation Evaluation. J. Clim. 2017, 30, 6823-6850. Available online: https://journals.ametsoc.org/view/journals/clim/30/17/jcli-d-16-0609.1.xml (accessed on 13 January 2021). [CrossRef] [PubMed]

36. Zheng, C.; Zhao, C.; Zhu, Y.; Wang, Y.; Shi, X.; Wu, X.; Chen, T.; Wu, F.; Qiu, Y. Analysis of influential factors for the relationship between PM2.5 and AOD in Beijing. Atmos. Chem. Phys. 2017, 17, 13473-13489. [CrossRef]

37. Tao, Z.; Wang, Z.; Yang, S.; Shan, H.; Ma, X.; Zhang, H.; Zhao, S.; Liu, D.; Xie, C.; and Wang, Y. Profiling the PM2.5 mass concentration vertical distribution in the boundary layer. Atmos. Meas. Tech. 2016, 9, 1369-1376. [CrossRef]

38. Stein, A.F.; Draxler, R.R.; Rolph, G.D.; Stunder, B.J.B.; Cohen, M.D.; Ngan, F. NOAA's HYSPLIT atmospheric transport and dispersion modeling system. Bull. Am. Meteorol. Soc. 2015, 96, 2059-2077. [CrossRef]

39. Li, J.; Carlson, B.E.; Lacis, A.A. Using single-scattering albedo spectral curvature to characterize East Asian aerosol mixtures. J. Geophys. Res. Atmos. 2015, 120, 2037-2052. [CrossRef]

40. Dubovik, O.; Smirnov, A.; Holben, B.; King, M.D.; Kaufman, Y.J.; Eck, T.F.; Slutsker, I. Accuracy assessment of aerosol optical properties retrieval from Aerosol Robotic Net- work (AERONET) Sun and sky radiance measurements. J. Geo-Phys. Res. 2000, 105, 9791-9806. [CrossRef]

41. Mori, T.; Ohata, S.; Morino, Y.; Koike, M.; Moteki, N.; Kondo, Y. Changes in black carbon and PM2.5 in Tokyo in 2003-2017. Proc. Jpn. Acad. Ser. B 2020, 96, 122-129. [CrossRef]

42. Sugimoto, N.; Matsui, I.; Shimizu, A.; Nishizawa, T.; Hara, Y.; Xie, C.; Uno, I.; Yumimoto, K.; Wang, Z.; Yoon, S.C. Lidar network observations of troposheric aerosols. SPIE 2008, 7153, 71530A. [CrossRef]

43. Lv, L.; Liu, W.; Zhang, T.; Chen, Z.; Dong, Y.; Fan, G.; Xiang, Y.; Yao, Y.; Yang, N.; Chu, B.; et al. Observations of particle extinction, PM2.5 mass concentration profile and flux in north China based on mobile lidar technique. Atmos. Environ. 2017, 164, 360-369. [CrossRef]

44. Koike, M.; Moteki, N.; Khatri, P.; Takamura, T.; Takegawa, N.; Kondo, Y.; Hashioka, H.; Matsui, H.; Shimizu, A.; Sugimoto, N. Case study of absorption aerosol optical depth closure of black carbon over the East China Sea. J. Geophys. Res. Atmos. 2014, 119, 122-136. [CrossRef]

45. Kim, K.W. Optical properties of size-resolved aerosol chemistry and visibility variation observed in the urban site of Seoul, Korea. Aerosol Air Qual. Res. 2015, 15, 271-283. [CrossRef]

46. Kim, K.W. Time-resolved chemistry measurement to determine the aerosol optical properties using PIXE analysis. J. Korean Phys. Soc. 2011, 59, 189-195. [CrossRef]

47. Jung, J.; Lee, H.; Kim, Y.J.; Liu, X.; Zhang, Y.; Gu, J.; Fan, S. Aerosol chemistry and the effect of aerosol water content on visibility impairment and radiative forcing in Guangzhou during the 2006 Pearl River Delta campaign. J. Environ. Manag. 2011, 90, 3231-3244. [CrossRef] [PubMed]

48. Cheng, Z.; Ma, X.; He, Y.; Jiang, J.; Wang, X.; Wang, Y.; Sheng, L.; Hu, J.; Yan, N. Mass extinction efficiency and extinction hygroscopicity of ambient PM2.5 in urban China. Environ. Res. 2017, 156, 239-246. [CrossRef] 
49. Hand, J.L.; Malm, W.C. Review of aerosol mass scattering efficiencies from ground-based measurements since 1990. J. Geophys. Res. 2007, 112, D16203. [CrossRef]

50. Matsui, H. Black carbon simulations using a size- and mixing-state-resolved three-dimensional model: 1 . Radiative effects and their uncertainties. J. Geophys. Res. Atmos. 2016, 121, 1793-1807. [CrossRef]

51. Bond, T.C.; Bergstrom, R.W. Light absorption by carbonaceous particles: An investigative review. Aerosol Sci. Technol. 2006, 40, 27-67. [CrossRef]

52. Cho, C.; Kim, S.W.; Lee, M.; Lim, S.; Fang, W.; Gustafsson, Ö.; Andersson, A.; Park, R.J.; Sheridan, P.J. Observation-based estimates of the mass absorption cross-section of black and brown carbon and their contribution to aerosol light absorption in East Asia. Atmos. Environ. 2019, 212, 65-74. [CrossRef]

53. Cheng, Y.; He, K.-B.; Zheng, M.; Duan, F.-K.; Du, Z.-Y.; Ma, Y.-L.; Tan, J.-H.; Yang, F.-M.; Liu, J.-M.; Zhang, X.-L.; et al. Mass absorption efficiency of elemental carbon and water-soluble organic carbon in Beijing, China. Atmos. Chem. Phys. 2011, 11, 11497-11510. [CrossRef]

54. Koch, D.; Schulz, M.; Kinne, S.; McNaughton, C.; Spackman, J.R.; Balkanski, Y.; Bauer, S.; Berntsen, T.; Bond, T.C.; Boucher, O.; et al. Evaluation of black carbon estimations in global aerosol models. Atmos. Chem. Phys. 2009, 9, 9001-9026. [CrossRef]

55. Laskin, A.; Laskin, J.; and Nizkorodov, S.A. Chemistry of atmospheric brown carbon. Chem. Rev. 2015, 115, 4335-4382. [CrossRef] [PubMed]

56. Xie, C.; Xu, W.; Wang, J.; Wang, Q.; Liu, D.; Tang, G.; Chen, P.; Du, W.; Zhao, J.; Zhang, Y.; et al. Vertical characterization of aerosol optical properties and brown carbon in winter in urban Beijing, China. Atmos. Chem. Phys. 2019, 19, 165-179. [CrossRef]

57. Yamaguchi, K.; Irie, H.; Damiani, A. Black carbon effects on the optical depth of light absorption. Quantitative evaluation of brown carbon contribution from long-term observation with skyradiometer in Chiba. In Proceedings of the 25th Japan Society of Atmospheric Chemistry, Chiba, Japan, 11-13 November 2020.

58. Giles, D.M.; Holben, B.N.; Eck, T.F.; Sinyuk, A.; Smirnov, A.; Slutsker, I.; Dickerson, R.R.; Thompson, A.M.; Schafer, J.S. An analysis of AERONET aerosol absorption properties and classifications representative of aerosol source regions. J. Geophys. Res. 2012, 117, D17203. [CrossRef]

59. Kirchstetter, T.W.; Novakov, T.; Hobbs, P.V. Evidence that the spectral dependence of light absorption by aerosols is affected by organic carbon. J. Geophys. Res. 2004, 109, D21208. [CrossRef]

60. Lin, C.C.; Yang, L.S.; Cheng, Y.H. Ambient PM2.5, black carbon, and particle size-resolved number concentrations and the angstrom exponent value of aerosols during the firework display at the lantern festival in Southern Taiwan. Aerosol Air Qual. Res. 2016, 16, 373-387. [CrossRef]

61. Nakayama, T.; Ikeda, Y.; Sawada, Y.; Setoguchi, Y.; Ogawa, S.; Kawana, K.; Mochida, M.; Ikemori, F.; Matsumoto, K.; Matsumi, Y. Properties of light-absorbing aerosols in the Nagoya urban area, Japan, in August 2011 and January 2012: Contributions of brown carbon and lensing effect. J. Geophys. Res. Atmos. 2014, 119, 721-739. [CrossRef]

62. Pitchford, M.; Malm, W.; Schichtel, B.; Kumar, N.; Lowenthal, D.; Hand, J. Revised algorithm for estimating light extinction from IMPROVE particle speciation data. J. Air Waste Manag. Assoc. 2007, 57, 1326-1336. [CrossRef]

63. Damiani, A.; Cordero, R.; Carrasco, J.; Watanabe, S.; Kawamiya, M.; Lagun, V.E. Changes in the UV lambertian equivalent reflectivity in the Southern Ocean: Influence of sea ice and cloudiness. Remote Sens. Environ. 2015, 169, 75-92. [CrossRef]

64. Bond, T.C.; Doherty, S.J.; Fahey, D.W.; Forster, P.M.; Berntsen, T.; DeAngelo, B.J.; Flanner, M.G.; Ghan, S.; Kärcher, B.; Koch, D.; et al. Bounding the role of black carbon in the climate system: A scientific assessment. J. Geophys. Res. Atmos. 2013, 118, 5380-5552. [CrossRef]

65. Buchard, V.; da Silva, A.M.; Colarco, P.R.; Darmenov, A.; Randles, C.A.; Govindaraju, R.; Torres, O.; Campbell, J.; Spurr, R. Using the OMI aerosol index and absorption aerosol optical depth to evaluate the NASA MERRA Aerosol Reanalysis. Atmos. Chem. Phys. 2015, 15, 5743-5760. [CrossRef] 